\title{
Assessment Indices for the Seismic Vulnerability of Existing R.C. Buildings
}

\author{
G. E. Thermou ${ }^{1, \hbar \S}$ and S. J. Pantazopoulou ${ }^{2}$ \\ ${ }^{1}$ Department of Civil Engineering, Aristotle University of Thessaloniki, 54124 Thessaloniki, Greece \\ ${ }^{2}$ Department of Civil Engineering, Demokritus University of Thrace, 67100 Xanthi, Greece
}

\begin{abstract}
SUMMARY
The seismic vulnerability of old multi-storey reinforced concrete (R.C.) buildings reinforced with substandard details is assessed as a function of interstorey drift demand imposed by the design earthquake while considering brittle termination of elastic response of the critical members of the structure due to premature shear failure. Interstorey drift demand is related to column and wall translational stiffnesses which are expressed through analytical derivations in terms of the floor area ratios of gravity and lateral load bearing members in the critical floor. Interstorey drift capacity is related to the available transverse reinforcement and the axial load ratio of the vertical members. The significance of the area ratio of vertical members in the typical floor as an index of vulnerability is explored with reference to the limitations in the value of axial load ratio used in R.C. design in order to secure ductile flexural behavior, and also with reference to the stability index of gravity load bearing members. Interstorey Drift Spectra are derived for existing R.C. buildings suitable for rapid seismic vulnerability screening but also as a guide for rehabilitation of existing structures. Lightly reinforced or substandard reinforced concrete buildings that reportedly collapsed during previous earthquakes are used as example case studies in order to calibrate the proposed methodology.
\end{abstract}

KEY WORDS: assessment; buildings; drift; reinforced concrete; masonry; vulnerability

\section{INTRODUCTION}

The progress made in earthquake engineering over the last few decades has had such a stunning influence on design and detailing practices in the area of reinforced concrete (R.C.) construction that the level of safety provided by modern structures designed according with the new philosophies bears no relationship with that of structures built in the former years. Yet, such structures abound, accounting for more than $80 \%$ of the built inventory worldwide. Recent earthquakes have repeatedly highlighted the serious vulnerability of these older structures, which have on occasion proved to be lethal to human life. Old, substandard reinforced concrete structures throughout the world exist, not only due to poor workmanship, poor material quality, and compounded problems due to ageing and misuse. Their biggest handicap is that they were built at times when general understanding about the importance of reinforcement detailing was still at its infancy. In the period referred to, the design philosophy was based on allowable stress design (mainly considering gravity loads, without adequate provision for seismic detailing), and therefore there was no control of the mode of failure and the corresponding deformation capacity of the individual members. Codes of design and detailing practice have evolved through the years converging to today's high standard; structures built in previous years do not follow any single standard: each represents a snapshot

\footnotetext{
$\$$ Correspondence to: Georgia E. Thermou, Filopimenos 2, 54640, Thessaloniki, Greece

§ Email: gthermou@otenet.gr
} 
of the practice followed in the specific time of their construction. But if a general attribute may be sought to describe old existing construction, it would be: light reinforcing details, frequently unfavorable distribution of stiffness and mass, and complete lack of any capacity design considerations. As a rule, in former codes seismic coefficients were assigned low values. Since then, these have been reset to $3 \div 4$ fold their original values (e.g. [1]).

From the point view of policy planning what is needed is a rapid screening method by which those reinforced concrete structures that are most likely to collapse in a significant earthquake can be screened out from the multitude. Figures 1(a), 1(b) depict pictures from two residential, two-storey reinforced concrete houses in Vartholomio, Western Peloponesse, that were subjected to the 6.5 Magnitude in the Richter scale of the 6/8/2008 Pyrgos (Greece) earthquake. Both were built in the early 1980's, with similar materials and methods; the one that collapsed (Figure 1(b)) featured a soft first storey, whereas the other, with masonry infills in the first storey, sustained serious damage without collapse. It may be shown by straightforward calculation that due to their small size the base shear attracted by the two structures was not excessive; the collapsed structure failed at a low displacement, equal to $25 \%$ of the yield value, i.e. while still in the elastic range. Thus, it was not lack of flexural inelastic deformation capacity, but lack of stiffness and shear strength that led it to collapse. In buildings with the pathogenicity described, the reduction of seismic displacements through control of the lateral stiffness is vital for the survival of the building during strong ground motion (Figures 1(c) and 1(d)).

(a)

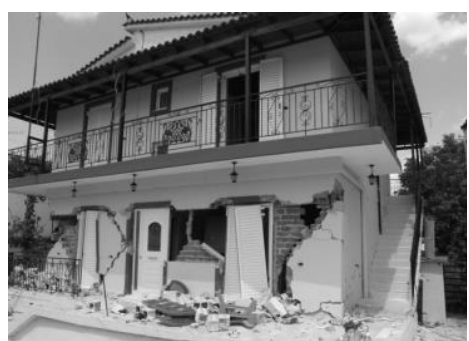

(b)

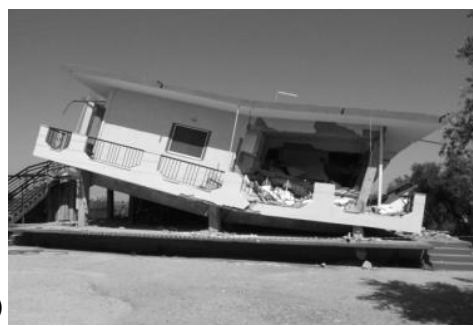

Andravida Earthquake (2008), $M=6.5$, Elastic response spectra of horizontal components

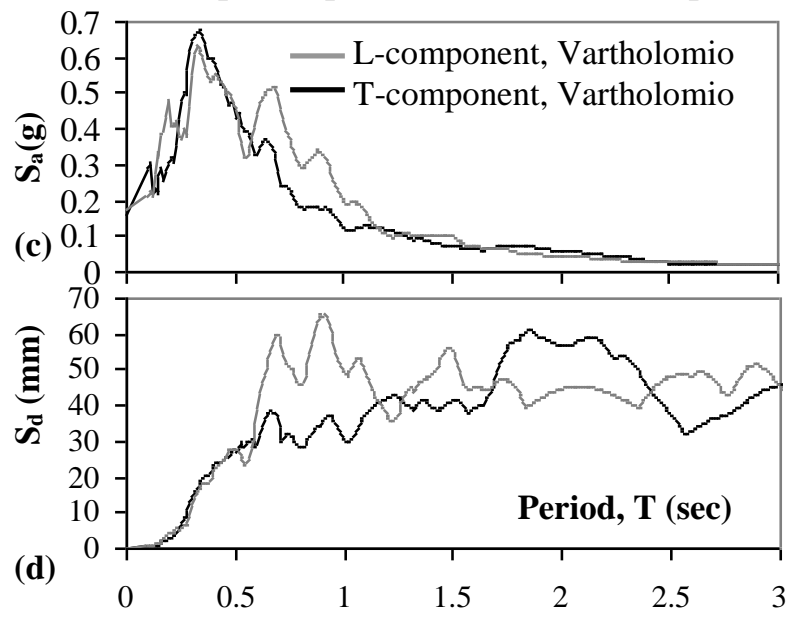

Figure 1. (a); (b) Residential houses in Vartholomio; (c); (d) Andravida (Pyrgos, Greece) Earthq. (8 June 2008), elastic response spectra (total Acceler., relative Displac.) of horizontal components.

In the present paper, damage of reinforced concrete (R.C.) structural systems with masonry infill walls is investigated as a function of the area of the vertical members and the interstorey drift of the critical floor. Minimum requirements in terms of the area of R.C. columns and masonry infill walls are established in order to limit drift demand to levels below the drift capacity (i.e. to control the risk of collapse or severe damage).

The proposed methodology is used to investigate the seismic vulnerability of older R.C. buildings, with particular emphasis on buildings that have collapsed during previous earthquakes, in an attempt to test its accuracy as a practical tool for identification of structures that are in dire need of detailed seismic assessment. 


\section{AREA-RATIO OF VERTICAL LOAD BEARING MEMBERS AS AN INDEX OF VULNERABILITY}

Today, identifying seismically deficient structures is usually treated as an assessment issue, which requires the estimation of the pushover curve to lateral loads. For a large number of existing buildings, this procedure involves disproportionally great effort compared to the uncertainty related to the details and the actual morphology of the structural system. The number of floors, the floor area and the area of the vertical members are the only data readily available for most existing R.C. buildings. Required information such as reinforcing details are often not available for the wide inventory of existing structures particularly in the developing world where structures were often built without drawings, or with drawings that do not necessarily agree with the built structure. The only option in situations where no data is available, is to resort to the typical practice of the era (as to the usual amount and layout of reinforcement), in the region where the building is located. The challenge is, using this limited data, to single-out those buildings that present higher vulnerability. The most meaningful diagnostic tools for direct and fast assessment are: (i) the index of sway of the building (this is the ratio of second order P- $\Delta$ effects to first order seismic moments in any floor); (ii) its fundamental period and (iii) its fundamental shape of vibration (this can be estimated either through simple Rayleigh type iteration, or can be approximated through simplified expressions provided that the building's tendency towards a shear or a flexural type response can be safely postulated). Deviation of these indices from the normal range of values suggests an abrupt change of mass or stiffness. It is shown below, that all these characteristics depend on a single parameter which is the ratio of the area and orientation of the vertical members to the plan floor area of the building. This is not a novel concept: it was the basic rule of thump used 50 years ago to built earthquake-safe structures. For example, a relevant paragraph of the 1959 seismic Design Code of Greece [2] is worth noting: the reduction of the masonry infill walls in any floor is not allowed to exceed $25 \%$ of the area of the masonry infill walls occupied by successive floors. On the contrary, an increase of stiffness of the structural members to an equal amount with the reduction of the total area of the masonry infill wall sections is necessary. Moreover, the reinforced concrete walls will have to be arranged in such a way as the total area of the R.C. walls in any storey in each direction of loading to be at least equal to 2\%o of the total floor plan area of the stories above. Thus, for a five storey building with a floor plan area of $100 \mathrm{~m}^{2}$, the minimum wall area required in the first floor would be $2 \times 2 \% o \times 5 \times 100=2 \mathrm{~m}^{2}$.

The area-ratio of vertical members has been used repeatedly throughout the world as a rapid-screening vulnerability index: it was used for classification of the seismic risk posed by older buildings in 1968 after the Tokachiken Oki earthquake [3], and more recently in Turkey ([4], [5], [6]). In general, when the area ratio values are either very high or very low, the result is consistent with field observation. But uncertain conclusion is not rare with usual intermediate values of the index. For example, the structure in Figure 1(b) had an area-ratio index of columns in the floor plan of about $1 \%$ which, for a two storey structure such as this, is not infrequent - in this case the area ratio of the columns fails to capture the structure's tendency to failure. Based on the results of the present work, this limitation is owing to the fact that detailing, as a factor responsible for premature failure, is not properly reflected in the value of the area-ratio index.

It is noted that the area-ratio of vertical load bearing elements is commonly used in the preliminary design phase even for new R.C. buildings, in order to control the normalized axial load $\left(v=W / \Sigma A_{c} f_{c}^{\prime}\right)$ to values below a limit of 0.4 (for symmetrically reinforced cross sections such as columns). This limit approximates the axial load at a balanced failure condition (simultaneous concrete compression crushing and bar tension yielding). This practice is 
intended to prioritize longitudinal reinforcement yielding to occur prior to concrete compression zone crushing thereby securing adequate flexural ductility of the individual members. For example, with reference to the N-M interaction diagram of a typical column of rectangular cross section (Figure 2(a)), the grey area highlights the range of acceptable values of compressive axial load (normalized in the plot with the nominal crushing load, $\Sigma A_{c} f_{c}^{\prime}$ ). Note that the total axial load at the base of an $n$-storey building is:

$$
N_{\text {total }}=W=n \cdot W_{f}
$$

where $W_{f}=\hat{g} \cdot A_{f}$ is the factored vertical load of the typical $i$-th floor, including self-weight, whereas $\hat{g}$ is the factored distributed load (in $\mathrm{kN} / \mathrm{m}^{2}$ ).

Thus, from simple statics it is evident that the average column axial load ratio, $v$, in the $1^{\text {st }}$ storey, is inversely proportional to the column area ratio:

$$
v=\frac{W}{f_{c}^{\prime} \cdot \sum A_{c}}=\frac{n \cdot W_{f}}{f_{c}^{\prime} \cdot \rho_{c} \cdot A_{f}}=\frac{n \cdot \hat{g}}{\rho_{c} \cdot f_{c}^{\prime}}=\frac{n}{\rho_{c}} \cdot \frac{\hat{g}\left(\mathrm{kN} / \mathrm{m}^{2}\right)}{1000 \cdot f_{c}^{\prime}(\mathrm{MPa})}
$$
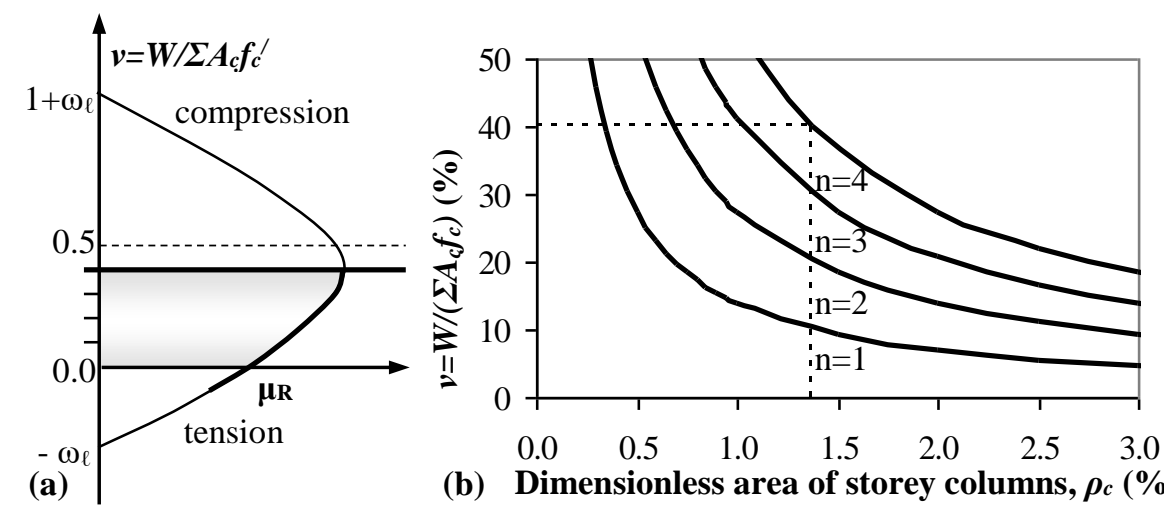

(b) Dimensionless area of storey columns, $\rho_{c}(\%)$

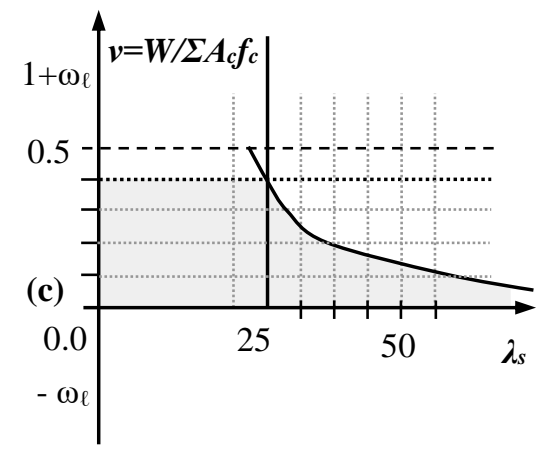

(d)

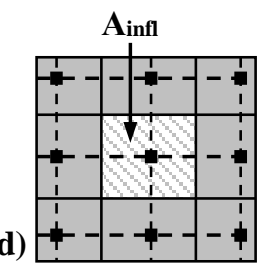

Figure 2. (a) Interaction diagram for vertical members (Parameter $\omega_{\ell}$ is the mechanical ratio of longitudinal reinforcement over the column section); (b) Diagram of dimensionless axial load, $v$, vs dimensionless area of storey columns, $\rho_{c} ;$ (c) Dimensionless axial load, $v$, vs slenderness of vertical members, $\lambda_{s} ;$ (d) column tributary area.

Figure 2(b) plots the required column area ratio, $\rho_{c}$, against the resulting axial load ratio for factored $\hat{g} /\left(1000 \cdot f_{c}{ }^{\prime}\right)=0.14 \%$, and different number of storeys in the structure $(n=1,2,3,4)$. The dashed line represents the balanced failure limit in the value of $v$. Note that for a fourstorey building, columns must occupy at least $1.4 \%$ of the first floor plan area to satisfy this limit.

The column area ratio, through its influence on $v$ has also a significant role in controlling the column slenderness and the sway index of the building; these two parameters may be 
considered auxiliary indicators of seismic vulnerability. For example, according with EC2 [7], second order effects should be considered if the column slenderness, $\lambda_{s}$, exceeds the limit:

$$
\lambda_{s}=\ell_{o} / i \leq \max \{25,15 / \sqrt{v}\}
$$

The curve in Figure 2(c) bounds the regions between the non-slender (grey area) and slender column design. It is clear that as the axial load ratio increases approaching the 0.4 limit, the acceptable value of $\lambda_{s}$ decreases, rendering the design for a given $\rho_{c}$ value, more critical. A note of caution here is required, as the validity of this analysis is reduced when the distribution of the vertical members in the floor plan is non-uniform. In this case the axial load ratio of a member in the $i^{\text {th }}$ floor may deviate significantly from the estimated mean value of $v$. This value should be corrected by coefficient $\delta_{j}$ (Figure 2(d)) for individual members:

$$
v_{j}=v_{a v e} \pm \delta_{j}
$$

where, $\delta_{j}=\hat{g} /\left(1000 \cdot f_{c}\right) \cdot n \cdot\left(1 / \rho_{c}-A_{\text {inff }} / A_{c, j}\right) \leq 0.2 v_{\text {ave }}$ estimates the local increase/decrease in the tributary plan area of the column from the average value implied by $\rho_{c}$ (hatched area in Figure 2(d)).

For example, for the building with the floor plan presented in Figure 3(a), which collapsed during the 1999 Athens Earthquake, the columns' and walls' area ratio in the floor plan was estimated equal to $1.35 \%$ (walls' ratio in $\mathrm{z}$ direction: $0.12 \%$, whereas in the y direction: $0.31 \%$ ). The external frame indicated in Figure 3(a) was selected for assessment (Figure 3(b)). The unfactored axial load ratios for the four columns were estimated from left to right equal to $v_{(40 / 70)}=0.09, \boldsymbol{v}_{(\mathbf{3 5} / \mathbf{3 5})}=\mathbf{0 . 4 1}, \boldsymbol{v}_{(\mathbf{4 0 / 6 0 )}}=\mathbf{0 . 1 9}, v_{(40 / 70)}=0.07$. The column slenderness values were estimated equal to $\lambda_{s(40 / 70)}=41.67, \lambda_{s(35 / 35)}=47.61, \lambda_{s(40 / 60)}=41.66, \lambda_{s(40 / 70)}=41.67$; note that slenderness of columns 35/35 and 40/60 (in bold) exceeds the limit defined by Equation (3). The Rayleigh iteration method yielded $T=1.24 \mathrm{sec}$ (excessive for a 4-storey building), and shape $\Phi^{T}=[1.00,0.997,0.992,0.984]^{\mathrm{T}}$ (marked with soft storey formation), both confirming the anticipation of unfavorable response already identified by the violation of Equation (3) for two of the four columns.

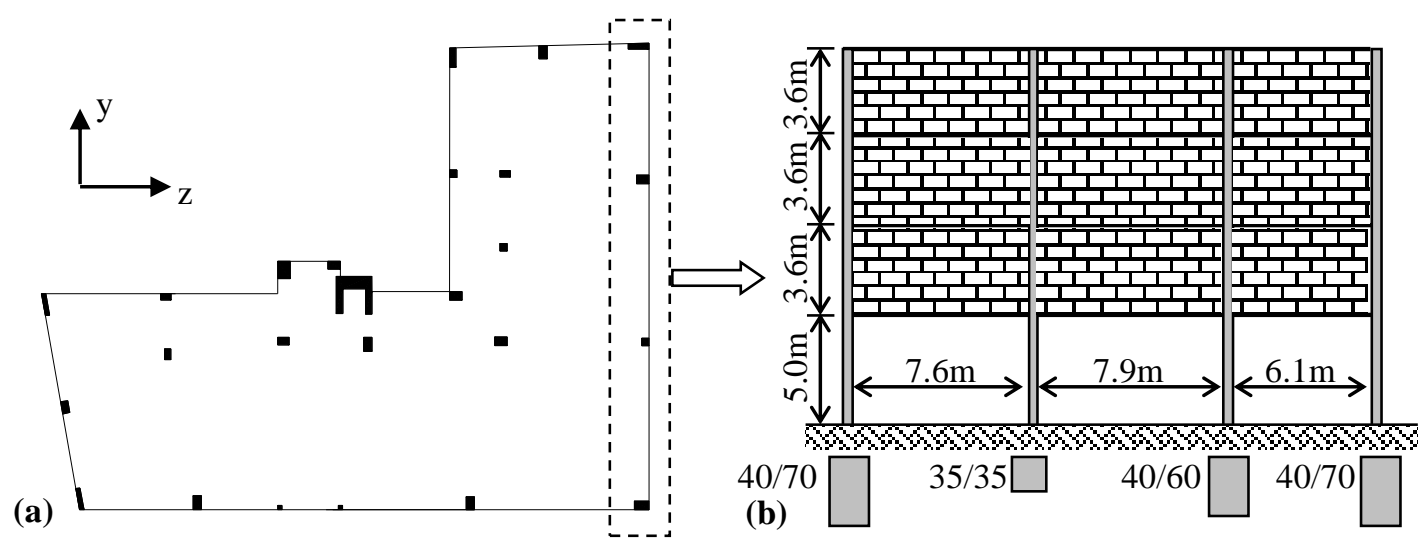

Figure 3. (a) Floor plan; (b) Frame under consideration (column dimensions in $\mathrm{cm}$ ).

\section{ESTIMATION OF BUILDING'S LATERAL STIFFNESS}

The buildings that are at the centre of the present study are of old type detailing, characterized by rigid diaphragms. Thus, sway during earthquakes in such structures is secured mainly by deformation of the vertical members. Furthermore, it is assumed that there 
are no vertical irregularities of mass and stiffness along the height of the building (i.e. there is a typical floor), and that the height of the storey is equal to $h_{i}$. For direct and relatively simple estimation of the lateral stiffness of the building, the multi-storey system is idealized by a generalized equivalent single-degree of freedom. The consequence of this assumption is that the building is considered to oscillate following always a unique shape of lateral displacement, which approaches the fundamental translational mode, whereas the contribution of the higher modes in this case is neglected. The reliability of the results is influenced greatly by the selection of the adopted shape function for the displacement shape. Given that the building deforms as a fixed cantilever in lateral transition, the translational coordinate in the shape of the fundamental mode increases from base to top, but the exact response shape is determined by the distribution of mass and stiffness in the individual floors. In the present paper, the fundamental oscillation shape, $\Phi$, is approached by three different alternative shape functions which are considered to represent the response of the majority of multi-storey residential buildings. Thus, buildings with relatively stiff diaphragms follow a shear type of behavior (Figure 4(a)), whereas buildings with relatively flexible horizontal members, present flexural type of behavior (Figure 4(c)). The case of Figure 4(b) (linear shape) is a theoretical idealization, its interesting feature being the uniform interstorey drift and hence the even distribution of damage along the height of the building. For a known response shape with a unit coordinate at the point of reference (here a unit translation at the top of the structure), the work equivalent stiffness of the entire structure results from the contribution of all the individual storeys of the building ( $n$ is the number of storeys):

$$
K=\sum_{i=1, n} K_{i} \cdot \Delta \Phi_{i}^{2}
$$
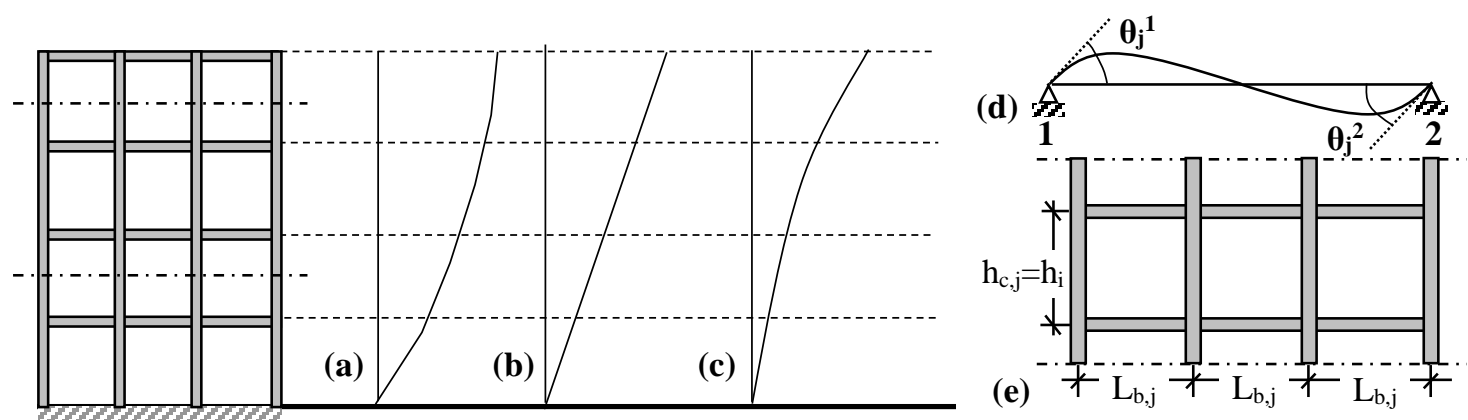

Figure 4. Lateral displacement profiles (a) shear-type; (b) triangular-type; (c) flexural-type; (d) Deflected member in a frame under lateral sway; (e) Definition of $h_{c, i}, L_{b, j}$.

Translational stiffness of a frame storey is estimated from the flexural stiffness of the individual members $(j=1,2, \ldots M)$, which develop flexural moments at the member ends 1 and 2 due to the respective chord rotations $\theta_{j}{ }^{1}, \theta_{j}^{2}$ under the applied lateral deflection shape, $\Phi$ (Figure 4(d)); to establish the work equivalent stiffness the structure is assumed to also undergo a virtual displacement pattern which, for convenience, is taken identical to the deflected shape, i.e., $\delta \Phi=\Phi$. Thus, individual member ends undergo virtual rotations $\delta \theta_{j}{ }^{1}, \delta \theta_{j}^{2}$ and the resulting virtual work expression for a single storey is:

$$
K_{i} \cdot \Delta \Phi_{i} \cdot \delta \Delta \Phi_{i}=\sum_{j=1, M} \frac{6 E I_{j}}{L_{j}} \cdot\left[\theta_{j}^{I} \cdot \delta \theta_{j}^{1}+\theta_{j}^{2} \cdot \delta \theta_{j}^{2}\right]
$$

Member end rotations are related to the interstorey drift magnitude of the storey under consideration, $\theta_{i}=\Delta \Phi_{i} / h_{i}$; the relationship is established by the requirement of moment 
equilibrium at the beam-column joints and depends on the relative stiffness ratio of the $n_{b}$ beams and the $n_{c}$ columns that converge at a typical floor joint: $\lambda=n_{b} E I_{b} \cdot h_{d} / n_{c} E I_{c} \cdot L_{b}$ (Figure 4(e)). Thus, beam ends rotate by the amount $\theta_{i j}{ }^{1}=\theta_{i, j}{ }^{2}=(1 / \lambda+1) \theta_{i}$; column ends rotate by the amount, $\theta_{i, j}{ }^{1}=\theta_{i, j}{ }^{2}=(\lambda 1+\lambda) \theta_{i}$. Assuming a representative average value of $\lambda$ for the entire storey and using the above result, Equation (5) for the $i$-th floor stiffness expression becomes:

$$
\begin{aligned}
& K_{i} \Delta \Phi_{i} \cdot \delta \Delta \Phi_{i}=K_{i} \cdot \Delta \Phi_{i}^{2}=\sum_{j=1, M} \frac{6 E I_{j}}{L_{j}} \cdot\left[\theta_{j}^{1} \cdot \delta \theta_{j}^{1}+\theta_{j}^{2} \cdot \delta \theta_{j}^{2}\right]= \\
& \underbrace{\sum_{j=1, M_{b}} \frac{12 E I_{b, j}}{L_{b, j}} \cdot\left(\frac{1}{\lambda+1}\right)^{2} \cdot \frac{\Delta \Phi_{i}^{2}}{h_{i}^{2}}}_{\text {contribution of the } M_{b} \text { beamsin the floor }}+\underbrace{\sum_{j=1, M_{c}} \frac{12 E I_{c, j}}{h_{c, j}} \cdot\left(\frac{\lambda}{\lambda+1}\right)^{2} \cdot \frac{\Delta \Phi_{i}^{2}}{h_{i}^{2}}}_{\text {contribution of the } M_{c} \text { columnsin the floor }}
\end{aligned}
$$

Substituting for the column length, $h_{c, j}$, the storey height, $h_{i}$, the above simplifies to:

$$
\begin{aligned}
& K_{i} \cdot \Delta \Phi_{i}^{2}=\sum_{j=1, M} \frac{6 E I_{j}}{L_{j}} \cdot\left[\theta_{j}^{1} \cdot \delta \theta_{j}^{1}+\theta_{j}^{2} \cdot \delta \theta_{j}^{2}\right]= \\
& =\left[\sum_{j=1, M_{b}} \frac{12 E I_{c, j}}{h_{i}^{3}} \cdot \lambda n_{c} \cdot\left(\frac{1}{\lambda+1}\right)^{2}+\sum_{j=1, M_{c}} \frac{12 E I_{c, j}}{h_{i}^{3}} \cdot\left(\frac{\lambda}{\lambda+1}\right)^{2}\right] \cdot \Delta \Phi_{i}^{2}
\end{aligned}
$$

In the case of a frame with rigid diaphragms (where $\lambda \rightarrow \infty$ ), the first term in the above expression diminishes (i.e., $\lambda /(\lambda+1)^{2} \rightarrow 0$ ), whereas the second term (column contribution) is conserved (i.e., $\left.\lambda^{2} /(\lambda+1)^{2} \rightarrow 1\right)$. In that case, storey stiffness may be estimated from the summation of the stiffness of the storey's vertical members, i.e., columns, walls, as well as masonry infill walls. Thus, the work equivalent contributions of a typical storey with total stiffness $K_{i}$, to the stiffness $K$ of the building are estimated from:

$$
K=\sum_{i=l, N} K_{i} \cdot \Delta \Phi_{i}^{2}=\sum_{i=1, N}\left[\sum_{j=1, n_{c}} K_{i, j}^{c}+\sum_{k=1, n_{w c}} K_{i, k}^{w c}+\sum_{p=l, n_{w m}} K_{i, p}^{w w}\right] \cdot \Delta \Phi_{i}^{2}
$$

Expressions for estimating the translational stiffness for R.C. columns, $K_{j}^{c}$, R.C. and masonry walls, $K_{k}^{w c}$, and $K_{p}^{w m}$ are summarized in the Appendix.

Floor mass may be estimated from the floor area, $A_{f}$, and the average self weight per unit floor area, $g_{s . w}$, divided by the acceleration of gravity. Thus, $M_{i}=\gamma \cdot A_{f}$ (where $\gamma=\gamma_{c} t f, \gamma_{c}$ is the density of the reinforced concrete $=25 \mathrm{kN} / \mathrm{m}^{3}: 10 \mathrm{~m} / \mathrm{sec}^{2}$ and $t_{f}$ the equivalent thickness of the horizontal diaphragm).

Dual systems: In case of dual systems the structure is inherently very stiff, with a nominal drift at yielding in the order of $0.25 \%$. In this case, elastic stiffness is assumed for R.C. walls and masonry infill walls (the same expression is used for both types of walls but are differentiated with respect to the modulus of elasticity and the member's length (Appendix, comparison of Equations (A.2) and (A.4)). Hence, an equivalent area ratio for R.C. walls and masonry infill walls is defined in terms of masonry infill walls. Thus, the total storey stiffness, $K_{i}$, is given by:

$$
K_{i} \approx A_{f} / h_{i}\left(B_{c} \rho_{c, i}+B_{w m} \rho_{w m, i}^{e}\right)
$$


where:

$$
\begin{gathered}
B_{c}=E_{c} / 100, B_{w m}=E_{w m} /\left[\left(4 h_{i}^{2} / l_{m, a v e}^{2}+2.5\right)\right] \\
\rho_{w m, i}^{e}=\rho_{w m, i}+\left(4 h_{i}^{2} / l_{m, a v e}^{2}+2.5\right) /\left(4 h_{i}^{2} / l_{w, a v e}^{2}+2.5\right) E_{c} / E_{w m} \rho_{w c, i}
\end{gathered}
$$

For Frames: Storey stiffness, $K_{i}$, comprises the stiffness of columns and masonry infill wall contributions. Note that in frame structures, interstorey drift at yielding of the frame members is in the order of $0.5 \%$. At that stage the infill walls (which reach their strength at a much lower drift level), have attained ductilities in excess of 3 and stiffness is reduced from the above reference elastic value. Thus, for frame structures which are generally more flexible than dual systems, the following expression is used for infill wall stiffness (Appendix):

$$
K_{i} \approx A_{f} / h_{i}\left(B_{c} \rho_{c, i}+B_{w m}^{\prime} \rho_{w m, i}\right)
$$

where:

$$
B_{c}=E_{c} / 100, B_{w m}^{\prime}=0.1 \cdot f_{w k} \sqrt{1+h_{i}^{2} / l_{w, a v e}^{2}} / \Theta_{i}
$$

It is observed that in both Equations (10) and (13) derived for estimation of the total floor translational stiffness, expressions are a linear combination of the floor area ratios of columns and masonry infill walls, respectively. It is also noteworthy that the stiffness component of the masonry infills is an inverse function of storey drift $\Theta_{i}$ and therefore it diminishes with increasing lateral displacements. (Note that $B^{\prime}{ }_{w m} \leq B_{w m}$ which controls for low drift values).

\section{INTERSTOREY DRIFT SPECTRA FOR EXISTING R.C. BUILDINGS}

The Interstorey Drift Spectra (I.D.S.) for retrofitted buildings have been developed as a new design tool by Thermou et al. [8] for seismic upgrading of existing buildings. The I.D.S. enable the designer to inspect directly the consequences resulting from the selection of the retrofit scenario on the response characteristics of the structure at the local as well as at the global level. With the help of the I.D.S., it is possible to relate stiffness demand to the target response of the upgraded structure. Similar methods have been utilized in the past for the estimation of the seismic vulnerability of existing buildings [4].

In the approach studied in the present paper, interstorey drift is expressed as a function of the design displacement spectrum and the typical floor area ratios of columns, $\rho_{c, i}$, walls, $\rho_{w c, i}$, and masonry infill walls, $\rho_{w m, i}$, for R.C. frames with masonry infill walls. Thus, in the present application the derived I.D.S. are intended for assessment of existing R.C. construction, where the predisposition for damage of a structural system to a given seismic excitation scenario and hence a measure of the system's vulnerability is quantified by the expected interstorey drift.

\subsection{Methodology of derivation}

In the proposed methodology, demand is defined by the Type I elastic spectrum of Eurocode 8 [9], where demand in terms of acceleration for a design region $0.15 \mathrm{sec}<\mathrm{T}<2.00$ sec is defined by the following equations:

$$
\begin{gathered}
T_{B} \leq T \leq T_{C}: S_{a}(T)=a_{g} S \beta_{o} / q \\
T_{C}<T \leq T_{D}: S_{a}(T)=a_{g} S \beta_{o} / q\left[T_{C} / T\right]
\end{gathered}
$$


In the present work, peak ground acceleration (pga), $\alpha_{g}$, is considered a parameter of study. According to Eurocode 8 [9] the following values apply for subsoil class B: $S=1.2, \beta_{o}=2.5$, $T_{B}=0.15 \mathrm{sec}, T_{C}=0.5 \mathrm{sec}$, $\kappa \alpha q q=1$. Upon substitution of these values in Equations (15a) and (15b) demand in terms of spectral displacements, $S_{d}$, for period values till $2.00 \mathrm{sec}$ is defined by:

$$
\begin{aligned}
& 0.15 \leq T \leq 0.50: S_{d}(T)=0.076 \alpha_{g} T^{2} \\
& 0.50<T \leq 2.00: S_{d}(T)=0.038 \alpha_{g} T
\end{aligned}
$$

Considering constant floor plan geometry along the height of the building and constant stiffness for the free vibration shape functions examined in the present paper, the expression for period $T$ for an $n$-storey building is approximated by [4]:

$$
T=2 \pi / \omega \doteq 4 n \sqrt{M_{i} / K_{i}}=4 n \cdot Q_{i}
$$

The fundamental period of the system is estimated after substitution of the storey mass, $M_{i}$, and Equations (10) or (13) in Equation (17) [4]. Further substitution of the result for $T$ in Equation (16) relates displacement demand, $S_{d}$, with the floor area ratios of vertical members contained in $Q_{i}$, which is defined as follows:

$$
\begin{array}{ll}
\text { For Dual systems: } & Q_{i}=\left[\gamma h_{i} /\left(B_{c} \rho_{c, i}+B_{w m} \rho_{w m, i}^{e}\right)\right]^{p .5} \\
\text { For Frames: } & Q_{i}=\left[\gamma h_{i} /\left(B_{c} \rho_{c, i}+B_{w m}^{\prime} \rho_{w m, i}\right)\right]^{p .5}
\end{array}
$$

Therefore, the $Q_{i}$ term depends on a composite area index of vertical members, which, in the case of dual systems, corresponds to $\left[\rho_{c, i}+\left(B_{w m} / B_{c}\right) \cdot \rho^{e}{ }_{w m, i}\right]$ (i.e. the sum of the area ratio of columns $\left(\rho_{c, i}\right)$ and the effective area ratio of walls and masonry infill walls $\left.\left[\left(B_{w m} / B_{c}\right) \cdot \rho^{e}{ }_{w m, i}\right]\right)$, whereas in the case of frames it corresponds to $\left[\rho_{c, i}+\left(B_{w m}^{\prime} / B_{c}\right) \cdot \rho_{w m, i}\right]$ (i.e. the sum of the area ratio of columns $\left(\rho_{c, i}\right)$ and an effective area ratio of masonry infill walls $\left.\left[\left(B_{w m}^{\prime} / B_{c}\right) \cdot \rho_{w m, i}\right]\right)$.

\subsection{Alternative lateral response shapes}

In the usual cases of buildings designed according to modern seismic design codes the elastic response shape lies between the shear and the flexural mode, though for old construction a shear response shape is more representative of actual behavior.

Stiffness discontinuity along the height of the building is detected in the elastic lateral response shape with a significant local increase of interstorey drift corresponding to that floor where discontinuity exists; this characteristic is responsible for the predisposition of damage localization in certain floors (e.g., in pilotis frames, i.e. frames with an open first storey). Thus, after the occurrence of yielding or other type of failure in the critical members, it is expected that inelastic deformation will further localize, therefore causing a increasing departure between the actual inelastic displacement profile and the assumed elastic response shape; thus, in extending from the elastic response to the inelastic estimate based on the equal-displacement rule, the resulting inelastic drift demands may be underestimated, for the benefit of maintaining simplicity in the procedure. The error introduced is acceptable in structures where failure is expected to occur by premature failure prior to, or immediately after flexural yielding. Furthermore, elimination of localized interstorey drift increase can be used as the driving consideration for retrofit: the stiffness required in the soft storey in order 
to eliminate local drift increase in the fundamental mode of vibration may be estimated and provided through the addition of properly dimensioned masonry infills or steel bracing [8].

Gülkan and Sozen [4] proposed a simple sinusoidal function as an approximation of the fundamental response shape of a shear-type building (Figure 4(a)):

$$
\Phi(x)=\sin (\pi x / 2 H)
$$

For this example, the interstorey drift of the first floor, $\Theta_{1}$, is given by:

$$
\Theta_{1}=S_{d} / h_{i} \Phi_{1}=S_{d} / h_{i} \sin (\pi / 2 n)
$$

Upon substitution of Equation (16) for the spectral displacement values, $S_{d}$ (which are given in terms of the fundamental period of the building) a design spectrum for the first storey drift demand under the design earthquake is extracted; for the two alternative building types considered above (Equations (18a) and (18b), respectively), the relevant expressions are:

$$
\begin{aligned}
& 0.15 \leq T \leq 0.50: \Theta_{1}=1.216 a_{g}\left(n^{2} Q_{1}^{2}\right) / h_{i} \sin (\pi / 2 n) \\
& 0.50<T \leq 2.00: \Theta_{1}=0.152 a_{g}\left(n Q_{1}\right) / h_{i} \sin (\pi / 2 n)
\end{aligned}
$$

The above expressions specify the seismic demands in terms of the geometric characteristics of the typical floor plan of the building (these are, the floor area ratios $\rho_{c, i}$, $\rho_{w m, i}$, of the vertical members included in the $Q_{1}$ terms). It is concluded that in order to limit drift and therefore damage, $\Theta_{i}$ must remain below the tolerable drift capacity of the structure considered. Given the relationship of drift demand to floor area ratio of vertical members through the expression for $Q_{i}$ in Equation (21), it follows that in the pre-seismic assessment of a building, this index should not fall below a minimum limit, i.e.:

$$
\begin{gathered}
\rho_{c, i}+\left(B_{w m} / B_{c}\right) \rho_{w m, i}^{e} \geq \rho_{\min } \rightarrow \text { For Dual systems } \\
\rho_{c, i}+\left(B_{w m}^{\prime} / B_{c}\right) \rho_{w m, i} \geq \rho_{\min } \rightarrow \text { For Frames }
\end{gathered}
$$

Variable $\rho_{\min }$ is the minimum area ratio of vertical members that would be required in order to avoid damage. This depends on the number of storeys, the tolerable damage which is quantified in terms of interstorey drift capacity (i.e., it depends on the quality of detailing of the members; well detailed members may reach a chord rotation of $1 \%$ without significant damage, whereas poorly detailed members may fail at chord rotations less than $0.5 \%$ ). Due to the particular susceptibility of stirrups in poor concrete to corrosion, tolerable damage also depends on the quality of material (for example, reduced member stiffness may be considered in case of steel corrosion [10]). Furthermore, this relationship may be applied at any storey level (considering the floors above the storey under consideration as the reference number of storeys, $n$ ). The same criterion may be adjusted to be used at the critical level of short columns in structures that feature this characteristic (to account for the amplified drift demand within the length of the captive columns). In this particular case, the drift demand, $\Theta_{\text {fail, }}$, occurring within the length of the captive columns is related to the average storey drift, $\Theta_{i}$, by:

$$
\Theta_{f a i l, i}=\Theta_{i} \cdot h_{i} / h_{\text {capt }}
$$




\section{ASSESSMENT OF SHEAR STRENGTH}

A critical issue that needs to be examined in evaluating the above seismic demands is whether the building can attain the estimated demand values, $\Theta_{i}$, before termination of the response due to premature shear failure. If this is the case, then the seismic drift demands specified by Equation (21) cannot be realized. To evaluate the onset of failure, or reversely, the peak ground acceleration that may be tolerated by a structure with known floor area ratios of vertical elements, the elastic drift demand need to be multiplied by the nominal seismic shear strength, $V_{R d, t o t}$, divided by the nominal storey shear at flexural yielding of the columns, $V_{y, \text { tot }}$ (if the ratio $V_{R d, t o t} / V_{y, t o t}$ is less than 1). At a given interstorey drift magnitude the storey shear resistance is obtained as the sum of the corresponding resistances of the storey's vertical members. Clearly, due to the significance of the conclusion that rides upon the value of $V_{R d, t o t}$ it is important that a conservative estimate should be used in checking the value of the $V_{R d, t o t} / V_{y, t o t}$ ratio. Note here that all available code approaches for shear are based on an idealized Moersch truss, whereby the primary source of resistance is owing to the web reinforcement intersected by a plausible $45^{\circ}$ failure plane (critical crack path, Figure 5), $V_{w, j}{ }^{s t}$, corrected by a relatively minor concrete contribution, $V_{c, j}[7,9,11]$. In the case of lightly reinforced members it is important to note that, (a) if stirrups are widely spaced it is possible that a failure plane may develop without intersecting any stirrup, in which case $V_{w, j}{ }^{s t}$ should be set equal to zero, whereas (b) even when non-zero, $V_{w, j}{ }^{s t}$ may be very small due to the sparsity of stirrups; however in no case should it be significantly overcome by the magnitude of $V_{c, j}$, because in such a case, the applicability of the Moersch truss assumption would be questionable. From among the many models available in the literature, the expression adopted by EC8-Part 3 [12] has been calibrated to a large database of relatively small section, reversed cyclic column tests. It was used in the practical examples of the present paper, as it was found to produce the most conservative estimates for the shear strength of lightly reinforced members having such small section dimensions that practical stirrup spacing was of the same magnitude as the member size. According with this model, shear strength of an existing column member, $V_{\text {shear, }}$, is given by [12]:

$$
V_{\text {shear }, j}=\frac{1}{\gamma_{e l}}\left[\begin{array}{l}
\left(h_{j}-x_{j}\right) /\left(2 L_{s}\right) \cdot \min \left(N_{j} ; 0.55 A_{c, j} f_{c}^{\prime}\right)+\left(1-0.05 \min \left(5 ; \mu_{\Delta}^{p l}\right)\right) \cdot \\
0.16 \max \left(0.5 ; 100 \rho_{\ell, t o t, j}\right)\left(1-0.16 \min \left(5 ; L_{s} / h_{j}\right)\right) \sqrt{f_{c}^{\prime}} A_{c, j}+V_{w, j}^{s t}
\end{array}\right]
$$

where, $V_{w, j}{ }^{s t}$ corresponds to the contributions of the web reinforcement (stirrups) [13]:

$$
V_{w, j}^{s t}=A_{s t, j} f_{s t}\left(d_{j} / s\right)=\left\{\begin{array}{c}
0 \quad \text { for } \quad d_{j}<s \\
d_{j} / s \text { for } \quad d_{j} \geq s
\end{array}\right.
$$

$V_{w, j}{ }^{s t}$ is calculated for a stirrup stress, $f_{s t}$, equal to the value that the tie anchorage can support, which is generally less than the ideal stirrup yield stress, $f_{y, s t}$ (if stirrups open prior to yielding). Therefore, $f_{s t}=f_{y, s t} L_{b, a} / 0.7 L_{b} \leq f_{y, s t}$, where $L_{b, a}$ is the available anchorage length of the tie measured from the point where it is intercepted by a $45^{\circ}$ diagonal crack to the end hook and $L_{b}$ is the standard straight anchorage length for the bar diameter of the ties considered ([13], Figure 5).

The shear force required to develop flexural yielding in a frame member under lateral sway, $V_{y, j}$, (i.e. a zero moment value approximately at midspan of beams and at midheight of columns) is estimated from [14]. (Note that $h_{i}$ the free member length, equal to $h_{\text {capt }}$ for captive columns): 


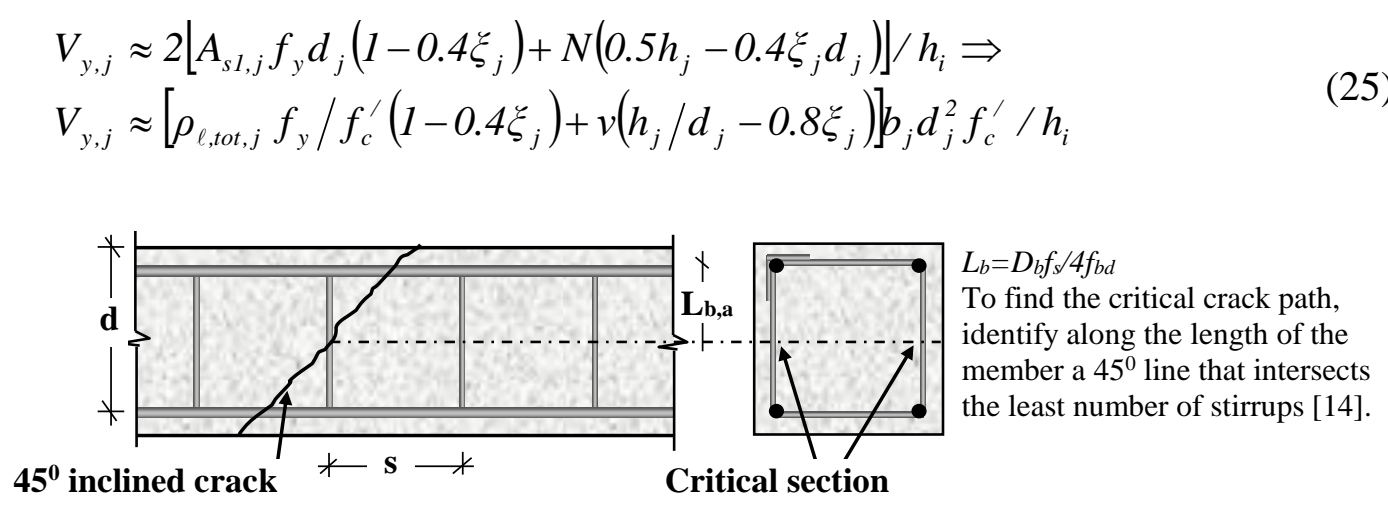

Figure 5. Calculation of the tie capacity based on tie anchorage conditions.

In the present case, storey shear demand and supply are obtained by summation of terms over the number of vertical storey members: $V_{R d, t o t}=\Sigma V_{\text {shear, } j}$ and $V_{y, t o t}=\Sigma V_{y, j}$. Comparison between $V_{R d \text {,tot }}$ and $V_{y, t o t}$ identifies the mode of likely failure for the storey in consideration (brittle elastic shear failure if $V_{R d, t o t}<V_{y, t o t}$; otherwise occurrence of flexural yielding is possible). If the former controls, then the storey drift at failure, $\Theta_{\text {fail, }}$ shear , is less than the corresponding value at flexural yielding, $\Theta_{y, i}$ :

$$
\Theta_{\text {fail }, i}^{\text {shear }}=\Theta_{y, i} V_{R d, t o t} / V_{y, t o t} \leq \Theta_{i}
$$

Therefore, the estimated design seismic drift demands (Equation 21) will be compared with the drift at yielding multiplied by $r=\min \left(V_{R d, t o t} / V_{y, t o t}, 1\right)$; if $r<1$, then, structural failure is anticipated at a reduced drift demand equal to $\Theta_{\text {fail, }}{ }^{\text {shear }}=r \Theta_{i}$.

\section{INTERSTOREY DRIFT ENVELOPES}

The expressions derived within the framework of the proposed methodology were used to construct the Interstorey Drift Spectra (I.D.S.) for existing R.C. buildings. In the parametric study expressions of the interstorey drift, $\Theta_{1}$, associated with target period values between $0.15 \mathrm{sec} \leq T \leq 0.50 \mathrm{sec}$ were utilized (Equation (21a)). This range of period values correspond to the plateau of the elastic design spectrum, hence to the maximum spectral acceleration values.

The extracted diagrams relate the anticipated peak storey drift, $\Theta_{1}$, to the floor area ratios of columns, $\rho_{c, i}$, walls, $\rho_{w c, i}$, and masonry infill walls, $\rho_{w m, i}$, in the first storey, the number of storeys $(n)$ and the quality of the construction materials. Equal drift demand envelopes were derived for existing buildings of different characteristics (i.e. interstorey drift demands $\Theta_{1}$ on the left-hand side of Equation (21a) were set equal to $0.50 \%, 0.75 \%, 1.00 \%, 1.25 \%, 1.50 \%$, $1.75 \%$ and $2.00 \%$; the required combinations of floor area ratios of columns and walls were estimated from the right-hand side of the same equation, implicit in the expression for $Q_{1}$ ). Parameters of study were the properties of concrete and masonry materials. Three categories of concrete and masonry were considered, respectively (Table I). The calculations were performed for buildings up to six storeys.

One class of interstorey drift envelopes is depicted in Figure 6, where the interstorey drift, $\Theta_{1}$, is related to the composite index of area ratios of vertical members in the first storey. In Figure 6, the group of curves corresponds to buildings with different number of storeys. The three plots correspond to different concrete categories where masonry infill walls have the same characteristics $f_{w k}=5 \mathrm{MPa}$. It is observed that for the same level of storey drift, $\Theta_{1}$, the 
required composite index of vertical members reduces with increasing quality of concrete. Curves become steeper as the number of storeys increases. Thus, the values which the composite indices $\left[\rho_{c, i}+\left(B_{w m} / B_{c}\right) \cdot \rho^{e}{ }_{w m, i}\right]$ or $\left[\rho_{c, i}+\left(B^{\prime}{ }_{w m} / B_{c}\right)^{\cdot} \cdot \rho_{w m, i}\right]$ must assume so as to limit the peak interstorey drift demand below a certain magnitude $\left(\Theta_{l}=0.50 \% \sim 2.00 \%\right)$ increase with the number of storeys, $n$.

Table I. Properties of the brick wall types and reinforced concrete categories used in the parametric study.

\begin{tabular}{cccc}
\hline Masonry infill type & Type I & Type II & Type III \\
\hline$f_{w k}(M P a)$ & 5 & 4 & 3 \\
\hline Concrete category & $\mathrm{C} 12 / 15$ & $\mathrm{C} 16 / 20$ & $\mathrm{C} 20 / 25$ \\
\hline$f_{c}^{\prime}(M P a), E_{c}(M P a)$ & 12,17321 & 16,20000 & 20,22361 \\
\hline
\end{tabular}

Diagrams similar to those of Figure 6 may be used to estimate the peak interstorey drift at the first storey when the number of storeys is the study variable. Note that for an elastic R.C. frame system where premature modes of failure are suppressed, yielding corresponds to an interstorey drift in the order of $0.5 \%$; thus, an estimated drift demand of $1 \%$ implies a ductility demand of 2 , whereas a drift demand of $2 \%$ corresponds to a ductility demand of 4 , etc. Clearly, for lightly reinforced substandard structures, it is wise to limit demand to a ductility of less than 1.5 (a drift in the range of $0.5 \%-0.75 \%$ ). But, if premature shear failure is likely, drift limits much less than $0.5 \%$ need to be also examined since they represent possible states of failure (i.e., values as low as $0.1 \%, 0.2 \%, 0.3 \%, 0.4 \%$ ).

(a)

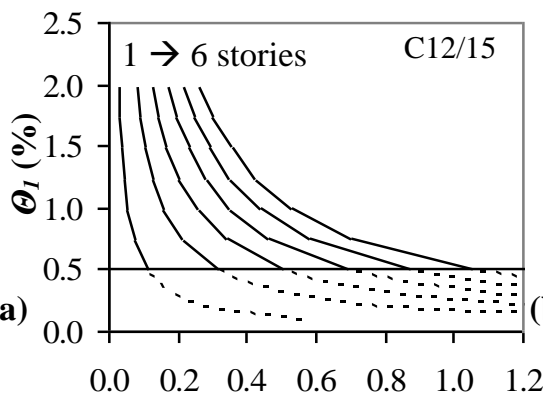

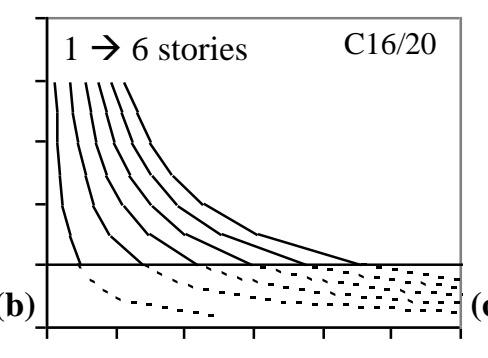

(c)

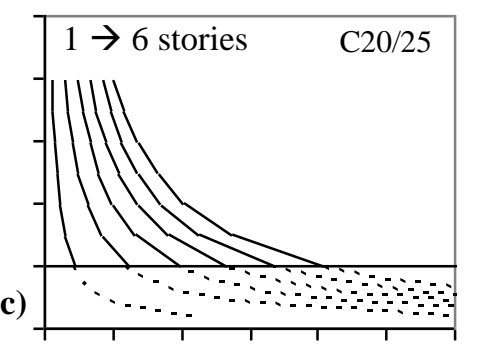

Composite area ratio of the vertical floor members $\left(\left[\rho_{c, i}+\left(B_{w m} / B_{c}\right) \rho^{e}{ }_{w m, i}\right]\right.$ or $\left[\rho_{c, i}+\left(B_{w m}^{\prime} / B_{c}\right)\right.$ $\left.\left.\rho_{w m, i}\right]\right)\left(* a_{g}\left(\mathrm{~m} / \mathrm{sec}^{2}\right), \%\right)$

Figure 6. Vulnerability curves that relate the required composite floor area ratio of vertical members so as not to exceed various levels of interstorey drift, $\Theta_{l}$. Drift demands that fall under the limiting value of $\Theta_{1}=0.5 \%$ are of interest for buildings susceptible to brittle failures. (It is noted the abscissa axis is a function of the peak ground acceleration, $a_{g}$ given in $\mathrm{m} / \mathrm{sec}^{2}$, which means that in order to get the values of the required composite area ratio of the vertical floor members for specific pga values, the area ratios obtained from the graph need to be multiplied by the $a_{g}$ values. For example, for $a_{g}=0.2 \mathrm{~g}=2 \mathrm{~m} / \mathrm{sec}^{2}$, the values in the horizontal axis of the plots should be multiplied by 2 ).

For assessment of buildings with a given number of storeys and specific concrete quality, diagrams, such as those depicted in Figures 7(a) and 7(b) may be derived for frames and dual systems, respectively. Thus, for various levels of maximum interstorey drift, the combination of the area ratio of columns and the effective area ratio of masonry infill walls (in the absence of R.C. walls, Figure 7(a)) or masonry infill and R.C. walls (expressed in terms of equivalent masonry infill wall area, Figure 7(b)) is examined.

Figure 7(c) plots for a given value of peak interstorey drift demand (i.e., equal damage), $\Theta_{l}$, the relationship between the area ratio of the first storey columns $\left(\rho_{c, i}\right)$ and the effective combined area ratio of masonry infill and R.C. walls (expressed by the term $\rho^{e}{ }_{w m, i}$ for dual 
systems) or the area ratio of masonry infill walls $\left(\rho_{w m, i}\right)$ for frames up to six storeys. Figure 7(c) is plotted for interstorey drift $\Theta_{l}=1 \%$ and a concrete quality $\mathrm{C} 16 / 20$. The required value of the area ratio of the first storey columns $\left(\rho_{c, i}\right)$ is kept constant in the three diagrams of each figure since the concrete quality remains the same, whereas the required value of the effective area ratio for masonry infill and R.C. walls expressed in terms of equivalent masonry infill wall area, $\left(\rho^{e}{ }_{w m, i}\right)$, or in terms of the area ratio of masonry infill walls, $\left(\rho_{w m, i}\right)$ (in the absence of R.C. walls), increases as the quality of masonry walls decreases. Furthermore, as the number of storeys increases, the required percentage of the two parameters increases for attainment of the same level of damage.
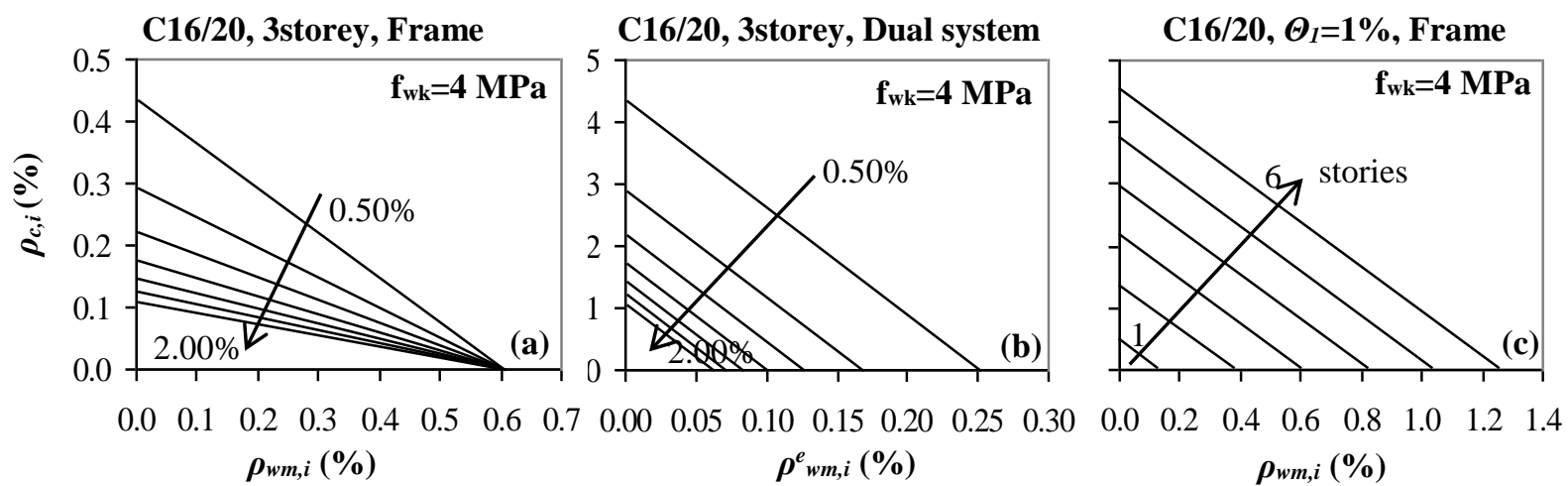

Figure 7. Vulnerability curves that relate the area ratio of columns, $\rho_{c, i}$, with: (a) the area ratio of masonry infill walls, $\rho_{w m, i}$, for 3-storey frames; (b) the area ratio of R.C. and masonry infill walls, $\rho^{e}{ }_{w m, i}$, for 3-storey dual systems; (c) the area ratio of masonry infill walls, $\rho_{w m, i}$, for a given quality of concrete if the interstorey drift demand is limited to $\Theta_{l}=1 \%$ (ductility of 2) for frames, where the number of floors is a variable.

\section{IMPLEMENTATION OF THE PROPOSED METHODOLOGY TO FRAME BUILDINGS COLLAPSED IN EARTHQUAKES}

The interstorey drift envelopes were utilized as an assessment tool for examining the behavior of two cases of old type construction. One case refers to a representative group of similar structures that were used as school-buildings; damage during the 2003 Bingöl earthquake in this group ranged from moderate to severe or even collapse [15]. A residential building that collapsed in the 1999 Athens earthquake is also used as the second case-study.

\subsection{Characteristics of the frame buildings}

School building typical structure: A typical floor plan layout of the group of school buildings is shown in Figure 8. Sixteen buildings were found to have identical floor plan with the number of stories above ground ranging from two to four [15]. The lateral load resisting system was regular in plan with a regular pattern of 43 columns in the typical floor. The columns were orthogonal with dimensions $0.3 \mathrm{~m} \times 0.5 \mathrm{~m}$. The thickness of the masonry infill walls was estimated to be $0.25 \mathrm{~m}$ for interior walls and $0.38 \mathrm{~m}$ for exterior walls. The building had window openings placed between columns in all the exterior walls along the $\mathrm{x}$-axis (Figure 8). Windows occupied approximately the upper half of the free storey height; the lower half comprised regular masonry infill walls. Thus, the free lengths of the columns between successive windows may be characterized as captive or short columns. Most of the school buildings in the group were three-storey frames (eleven out of sixteen) and thus the present study focuses on this sub-group. 


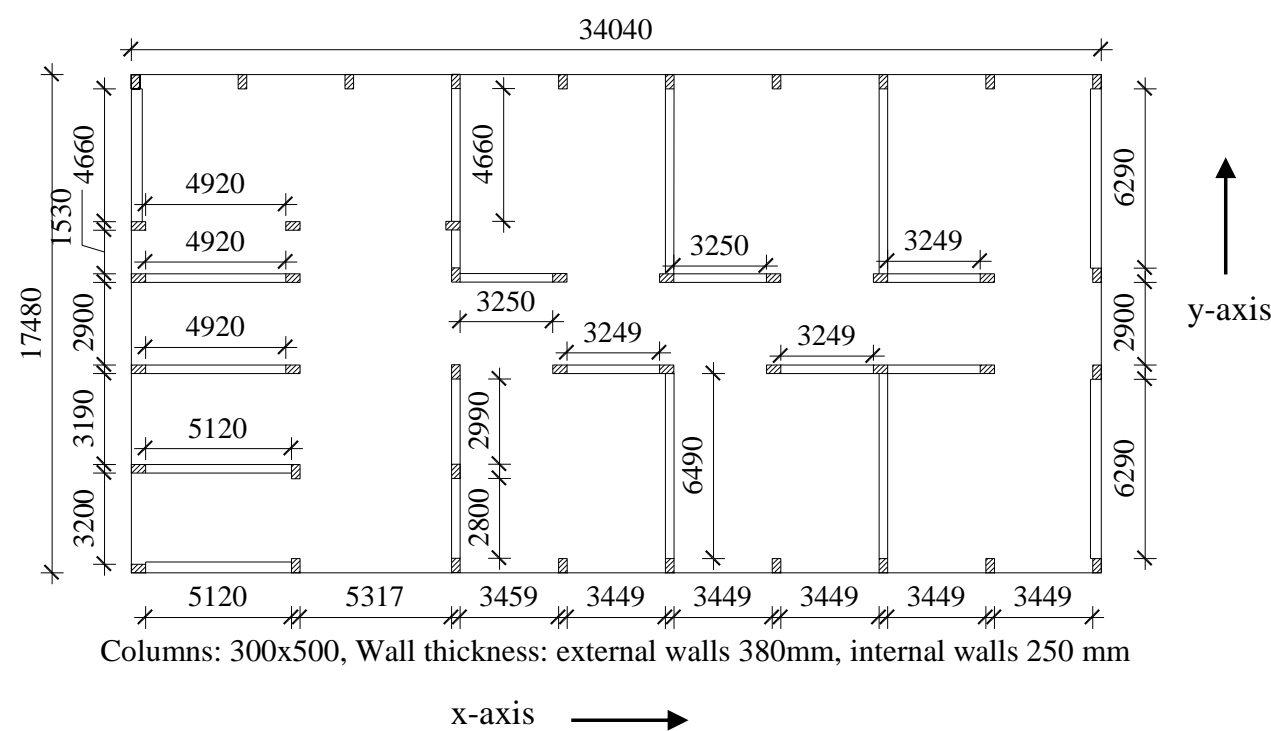

Figure 8. Typical floor plan of the group of school buildings [15] (dimensions in $\mathrm{mm}$ ).

Transverse reinforcement comprised stirrups of nominal diameter $\varnothing 8$ spaced at $250 \mathrm{~mm}$ with a steel stress at yield, $f_{y}=220 \mathrm{MPa}$ [15]. Assumptions were made regarding material properties and main steel ratio (explicit information regarding these two aspects was lacking in the reconnaissance reports) based on the data provided by Gür et al. [15] and Ramirez et al. [16] (total longitudinal reinforcement ratio in the columns was assumed to be in the range of $1 \%$ - higher assumed values would increase the discrepancy between shear and flexural strengths rendering the occurrence of a brittle failure even more likely- yield stress of longitudinal reinforcement, $f_{y}=300 \mathrm{MPa}$, nominal concrete compressive strength, $f_{c}^{\prime}=16 \mathrm{MPa}$, and masonry compressive strength, $\left.f_{w k}=4 \mathrm{MPa}\right)$. Both longitudinal and transverse reinforcement comprised smooth bars [15].

According to the floor plan of Figure 8, the area ratio of columns, $\rho_{c, i}$, was estimated to be: $\rho_{c, i}=1.08 \%$. The area ratio of the external and internal masonry infill walls, was estimated in both directions to be equal to: (i) in the X-x direction: $\rho_{w m, i}{ }_{i x t, x}=0.33 \%$ and $\rho_{w m, i}{ }^{i n t, x}=1.67 \%$, respectively, and (ii) in the y-y direction $\rho_{w m, i}{ }^{e x t, y}=1.10 \%$ and $\rho_{w m, i}{ }^{i n t, y}=1.59 \%$, respectively. The total area ratio of the masonry infill walls was $\rho_{w m, i}{ }^{x}=\rho_{w m, i}{ }^{e x t, x}+\rho_{w m, i}{ }^{i n t, x}=1.99 \%$ along the Xaxis, and $\rho_{w m, i}{ }^{y}=\rho_{w m, i}{ }^{e x t, y}+\rho_{w m, i}{ }^{i n t, y}=2.69 \%$ along the y-axis. The area ratio of the infill walls in the $\mathrm{x}-\mathrm{x}$ direction at the level of the captive columns is reduced to $\rho_{w m, i}{ }^{x}=\rho_{w m, i}{ }^{e x t, x}+\rho_{w m, i}{ }^{i n t, x}=0+1.67 \%=1.67 \%$.

The response of the 43 columns was differentiated depending on the direction of earthquake loading. In case that the direction of earthquake loading was parallel to the $\mathrm{x}$-axis as depicted in Figure 8, then 19 columns would have their strong axis $\left(h_{j}=500 \mathrm{~mm}\right)$ parallel to the $\mathrm{x}$-axis, whereas 24 columns would have their weak axis $\left(h_{j}=300 \mathrm{~mm}\right)$ parallel to the $\mathrm{y}$ axis. Based on this assumption and following the procedure presented previously, the results of the shear strength assessment of the ground floor columns are presented in Table II. As it is shown in the last column of Table II, the columns are estimated to have failed in shear well before flexural yielding. (Here, $V_{R d, t o t}=23 \% W_{t o t}, V_{y, t o t}=36 \% W_{t o t}$, where $W_{t o t}=10108.8 \mathrm{kN}$. According with this estimation, the building type considered is expected to survive an earthquake with peak ground acceleration $a_{g}<0.093 \mathrm{~g}$ estimated from the shear strength to the structure's weight ratio of $23 \%$ found above, when considering a coefficient of amplification $\beta_{o}=2.5$ as per EC8 [9]). Interstorey drift at column yielding was estimated using the "stick model" cantilever extending from the support to the point of inflection around the midheight of the column. Thus, $\Theta_{y, j}=1 / 3 \varphi_{y, j} L_{s}$, where $\left.\varphi_{y, j}=2.14 \varepsilon_{s y} / h_{j}[17,18]\right)$. Average interstorey drift at column yielding was estimated as $\Theta_{y, \text { ave }}=0.44 \%$ (Table II). Thus, elastic shear failure was 
expected to occur at the level of captive columns at a lower interstorey drift value equal to $\Theta_{\text {fail, } 1}^{\text {shear }}=\Theta_{y, \text { ave }} \cdot V_{R d, \text { capt }} / V_{y, \text { capt }}=0.44 \cdot 0.36=0.16 \%$ (Table II). The other columns of the first storey were expected to fail at $\Theta_{\text {fail, }}$ shear $=\Theta_{y, \text { ave }} \cdot V_{R d, t o t} / V_{y, t o t}=0.44 \cdot 0.23 / 0.36=0.29 \%$. (The estimated peak displacement demand was $S_{d}=11.6 \mathrm{~mm} \quad\left(\Theta_{l}=0.19 \%\right), \quad S_{d}=17.4 \mathrm{~mm}$ $\left(\Theta_{l}=0.29 \%\right), S_{d}=23.2 \mathrm{~mm}\left(\Theta_{l}=0.39 \%\right), S_{d}=29.1 \mathrm{~mm}\left(\Theta_{l}=0.48 \%\right)$ for the four levels of seismicity with peak ground acceleration of $a_{g}=0.24 \mathrm{~g}, 0.36 \mathrm{~g}, 0.48 \mathrm{~g}, 0.60 \mathrm{~g}$, respectively).

Table II. Shear strength assessment of the columns of the typical 3-storey school building.

\begin{tabular}{ccccccccccc}
\hline $\begin{array}{c}\text { Column } \\
\text { strong axis }\end{array}$ & $\begin{array}{c}\text { No of } \\
\text { columns }\end{array}$ & $\begin{array}{c}N_{j} \\
(\mathrm{kN})\end{array}$ & $v_{j}$ & $\begin{array}{c}\Theta_{y, j} \\
(\%)\end{array}$ & $\begin{array}{c}M_{y, j} \\
(\mathrm{kNm})\end{array}$ & $\begin{array}{c}V_{y, j} \\
(\mathrm{kN})\end{array}$ & $\begin{array}{c}L_{b, a} \\
(\mathrm{~mm})\end{array}$ & $\begin{array}{c}V_{w, j}{ }^{\text {st }} \\
(\mathrm{kN})\end{array}$ & $\begin{array}{c}V_{\text {shear }, j} \\
(\mathrm{kN})\end{array}$ & $\begin{array}{c}V_{\text {shear }, j}< \\
V_{y, j}\end{array}$ \\
\hline $\mathrm{x}$, full height & 18 & 235.1 & 0.10 & 0.32 & 142.5 & 95.0 & 232 & 21.7 & 77.6 & $\checkmark$ \\
\hline $\mathrm{x}$, captive & 1 & 235.1 & 0.10 & 0.32 & 142.5 & 190.0 & 232 & 21.7 & 77.6 & $\checkmark$ \\
\hline $\mathrm{y}$, full height & 16 & 235.1 & 0.10 & 0.54 & 80.7 & 53.8 & 132 & 12.3 & 37.3 & $\checkmark$ \\
\hline $\mathrm{y}$, captive & 8 & 235.1 & 0.10 & 0.54 & 80.7 & 107.6 & 132 & 12.3 & 37.3 & $\checkmark$ \\
\hline$\Theta_{y, \text { ave }}=0.44 \%$, & $V_{y, \text { tot }}=3621.1 \mathrm{kN}, V_{y, \text { capt }}=1050.8 \mathrm{kN}, V_{R d, \text { tot }}=2370.7 \mathrm{kN}, V_{R d, \text { capt }}=376.1 \mathrm{kN}$ \\
\hline
\end{tabular}

Residential building: The building considered in this example collapsed during the 1999 Athens earthquake. It was a three-storey moment resisting R.C. frame with masonry infill walls. Each storey was constructed in a different decade, i.e., the first storey in the mid ' $50 \mathrm{~s}$, the second storey in the mid " 60 s whereas the third storey in the mid " 70 s following the Greek seismic code of that era, known as the Royal Decree of 1959 [2]. The first storey was used as commercial space (practically open ground floor due to shop-windows), whereas the other two storeys were used as residential apartments.

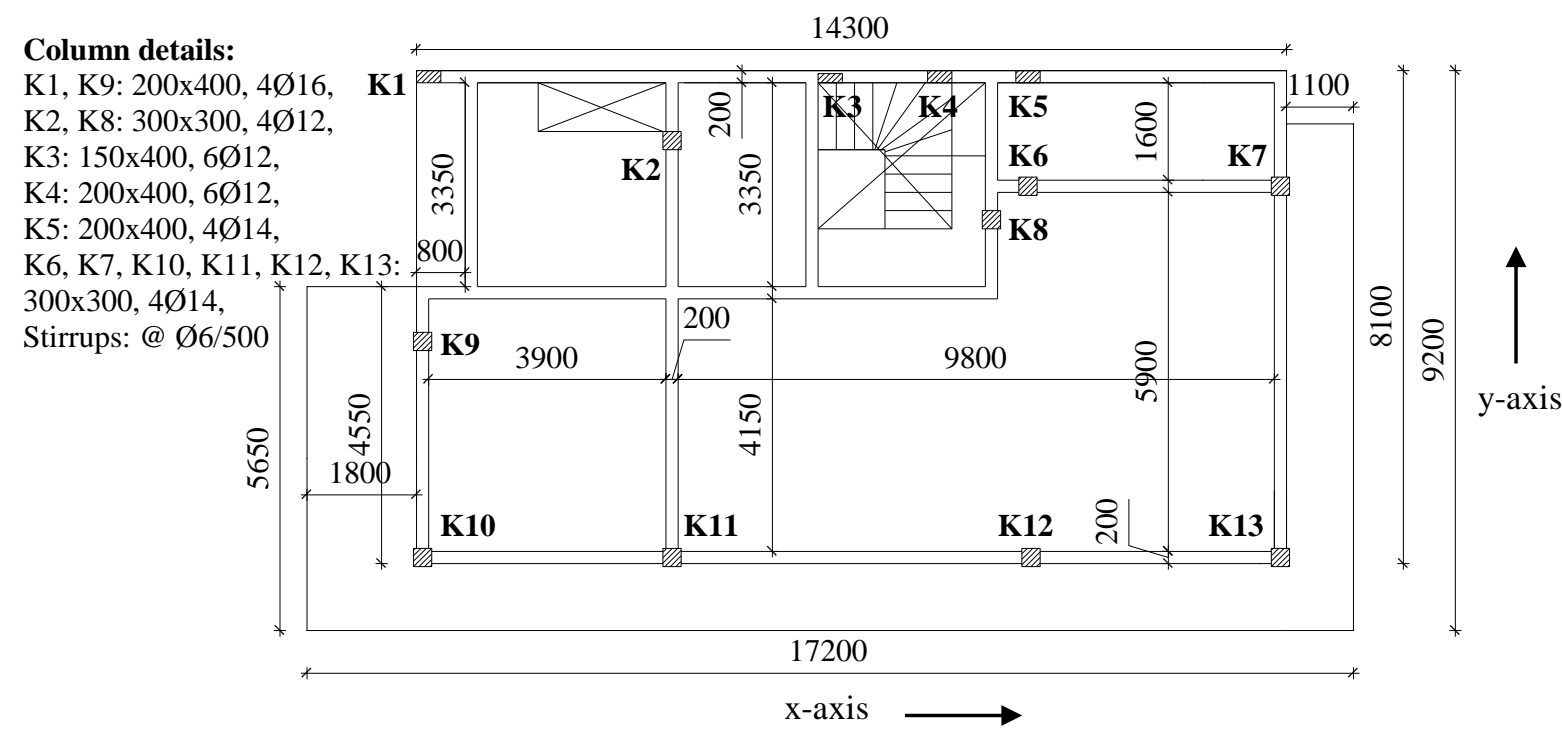

Figure 9. Typical floor plan for the moment-resisting frame system that collapsed during the 1999 Athens earthquake (dimensions in mm).

The typical floor plan of the moment resisting frame is shown in Figure 9. This building is characterized by a strong-beam-weak-column mechanism. The building featured various deficiencies; sparse arrangement of column stirrups at a spacing of $s=500 \mathrm{~mm}$, indirect supports (beam to beam connections), insufficient anchorages, no stirrups in the beam-column joints, bad connection of the ground floor columns to the foundation system, with semi rigid 
connections and large spans. Due to insufficient information relative to the construction materials, assumptions were made based mainly on field observation and the materials used for seismic applications of the era, according to DIN1045 [19] and DIN 488 [20]. Concrete quality was $\mathrm{Bn} 200$ (nominal cubic strength of $200 \mathrm{~kg} / \mathrm{cm}^{2}$ corresponding to a nominal concrete compressive strength $f_{c}^{\prime}=16 \mathrm{MPa}$ ), whereas the steel quality is representative of that being used for longitudinal reinforcement in the period of construction in Greece, StIII (steel yield strength $f_{y}=4200 \mathrm{~kg} / \mathrm{cm}^{2}$ or $420 \mathrm{MPa}$ ) and for stirrups StI (steel yield strength $f_{y}=2200$ $\mathrm{kg} / \mathrm{cm}^{2}$ or $220 \mathrm{MPa}$ ). Both longitudinal and transverse reinforcement comprised smooth bars. Masonry infill walls had an assumed compressive strength $f_{w k}=4 \mathrm{MPa}$.

Based on the available floor plans, the available area ratio of columns, $\rho_{c, i}$, was estimated to be equal to $\rho_{c, i}=0.98 \%$, whereas the floor area ratio of the masonry infill walls was $0 \%$ in the ground floor, and $\rho_{w m, i}{ }^{x}=4.68 \%$ along the x-axis and $\rho_{w m, i}{ }^{y}=2.62 \%$ along the $\mathrm{y}$-axis in the upper floors (a typical floor plan is depicted in Figure 9).

Table III. Shear strength assessment of the columns of the 3-storey residential building.

\begin{tabular}{lccccccccc}
\hline Columns & $\begin{array}{c}N_{j} \\
(\mathrm{kN})\end{array}$ & $v_{j}$ & $\begin{array}{c}\Theta_{y, j} \\
(\%)\end{array}$ & $\begin{array}{c}M_{y, j} \\
(\mathrm{kNm})\end{array}$ & $\begin{array}{c}V_{y, j} \\
(\mathrm{kN})\end{array}$ & $\begin{array}{c}L_{b, a} \\
(\mathrm{~mm})\end{array}$ & $\begin{array}{c}V_{w, j}{ }^{\text {st }}\left(V_{\text {shear }, j} V_{\text {shear }, j}\right. \\
(\mathrm{kN})\end{array}$ & $<V_{y, j}$ \\
\hline $\mathrm{K} 1$ & 121.6 & 0.09 & 0.56 & 74.1 & 49.4 & 182 & 0.0 & 24.1 & $\checkmark$ \\
\hline $\mathrm{K} 2$ & 367.9 & 0.26 & 0.75 & 67.3 & 44.9 & 132 & 0.0 & 26.9 & $\checkmark$ \\
\hline $\mathrm{K} 3$ & 222.2 & 0.23 & 0.56 & 83.6 & 55.8 & 182 & 0.0 & 26.2 & $\checkmark$ \\
\hline $\mathrm{K} 4$ & 52.1 & 0.04 & 0.56 & 54.2 & 36.1 & 182 & 0.0 & 19.8 & $\checkmark$ \\
\hline $\mathrm{K} 5$ & 88.8 & 0.07 & 0.56 & 56.2 & 37.4 & 182 & 0.0 & 22.1 & $\checkmark$ \\
\hline $\mathrm{K} 6$ & 132.3 & 0.09 & 0.75 & 46.0 & 30.7 & 132 & 0.0 & 15.5 & $\checkmark$ \\
\hline $\mathrm{K} 7$ & 312.5 & 0.22 & 0.75 & 68.0 & 45.4 & 132 & 0.0 & 24.3 & $\checkmark$ \\
\hline $\mathrm{K} 8$ & 225.8 & 0.16 & 0.75 & 49.8 & 33.2 & 132 & 0.0 & 20.1 & $\checkmark$ \\
\hline $\mathrm{K} 9$ & 215.4 & 0.17 & 0.56 & 90.1 & 60.1 & 182 & 0.0 & 30.0 & $\checkmark$ \\
\hline $\mathrm{K} 10$ & 216.3 & 0.15 & 0.75 & 56.3 & 37.5 & 132 & 0.0 & 19.6 & $\checkmark$ \\
\hline $\mathrm{K} 11$ & 383.5 & 0.27 & 0.75 & 76.7 & 51.1 & 132 & 0.0 & 27.8 & $\checkmark$ \\
\hline $\mathrm{K} 12$ & 378.2 & 0.26 & 0.75 & 76.0 & 50.7 & 132 & 0.0 & 27.5 & $\checkmark$ \\
\hline $\mathrm{K} 13$ & 256.6 & 0.18 & 0.75 & 61.2 & 40.8 & 132 & 0.0 & 21.6 & $\checkmark$ \\
\hline \multicolumn{7}{c}{$\Theta_{y, \text { ave }}=0.68 \%, V_{y, \text { tot }}=573.0 \mathrm{kN}, V_{R d, t o t}=305.7 \mathrm{kN}$} & \\
\hline
\end{tabular}

In case that the direction of earthquake loading was parallel to the x-axis, shear strength assessment of the ground floor columns is given in Table III following the simplified procedure described in the previous section. In all cases column shear strength was below the force level required to sustain flexural yielding; (thus, $V_{R d, t o t}=10 \% W_{t o t}, V_{y, t o t}=19 \% W_{t o t}$, where $W_{\text {tot }}=2973.1 \mathrm{kN}$. Considering the shear strength to the structure's weight ratio of $10 \%$ found above, it is concluded that the building would be able to sustain a design-type earthquake with a peak ground acceleration of $a_{g}=0.04 \mathrm{~g}$, assuming a response amplification factor $\beta_{o}=2.5$ ). According to the current Greek seismic design code [1] this demand does not satisfy even the lowest seismicity level. Estimated average interstorey drift at yielding was $\Theta_{y, a v e}=0.68 \%$ as listed in Table III. Owing to premature failure in shear, drift at failure was: $\Theta_{\text {fail, }}=\Theta_{y, a v e} \cdot V_{R d, \text { tot }} / V_{y, \text { tot }}=0.68 \cdot 0.10 / 0.19=0.36 \%$, i.e., well below the estimated peak demand. (The estimated peak displacement demand was $S_{d}=35.5 \mathrm{~mm}\left(\Theta_{l}=0.59 \%\right), S_{d}=53.2 \mathrm{~mm}$ $\left(\Theta_{l}=0.89 \%\right), S_{d}=71.0 \mathrm{~mm}\left(\Theta_{l}=1.18 \%\right), S_{d}=88.7 \mathrm{~mm}\left(\Theta_{l}=1.48 \%\right)$ for the four levels of seismicity with peak ground acceleration of $a_{g}=0.24 \mathrm{~g}, 0.36 \mathrm{~g}, 0.48 \mathrm{~g}, 0.60 \mathrm{~g}$, respectively). 


\subsection{Assessment using the interstory drift envelopes}

Both building types were assessed for four levels of seismicity with peak ground acceleration of $0.24 \mathrm{~g}, 0.36 \mathrm{~g}, 0.48 \mathrm{~g}$ and $0.60 \mathrm{~g}$. The vulnerability curves that relate the composite dimensionless index of area of the vertical floor members, $\left[\rho_{c, i}+\left(B_{w m} / B_{c}\right) \rho^{e}{ }_{w m, i}\right]$ or $\left[\rho_{c, i}+\left(B_{w m}^{\prime} / B_{c}\right) \rho_{w m, i}\right]$, for various levels of drift, $\Theta_{i}$ were constructed for $f_{c}^{\prime}=16 \mathrm{MPa}$ and $f_{w k}=4$ $\mathrm{MPa}$ in Figures 10(a) and 10(b) for the typical three-storey school building sample and the residential building, respectively. The vulnerability curves for the two three-storey buildings are differentiated owing to the different distributed floor masses.

School building typical structure: The required values of the composite index for vertical members in order to secure that drift demand lies below the limited drift capacity of the structure which was estimated as $\Theta_{\text {fail, },}=0.16 \%$ are marked by the arrows in Figure 10(a): the values are $2.6 \%, 4.0 \%, 5.3 \%, 6.6 \%$ for $a_{g}=0.24 \mathrm{~g}, 0.36 \mathrm{~g}, 0.48 \mathrm{~g}, 0.60 \mathrm{~g}$, respectively. If these values are compared with the available composite index as calculated for the characteristics of the school building for drift $\Theta_{\text {fail }, 1}=0.16 \%, \rho_{c, i}+\left(B^{\prime}{ }_{w m} / B_{c}\right) \rho_{w m, i}{ }^{x}=1.08+1.63 \cdot 1.67=3.8 \%$, it is concluded that the area ratios of the vertical members and the masonry infill walls was sufficient only for $a_{g}=0.24 \mathrm{~g}$ (note that for this level of drift $B^{\prime}{ }_{w m}=B_{w m}=325.4 \mathrm{MPa}, B_{c}=200$ $\mathrm{MPa}$ ). Thus, the typical building would be expected to fail in shear and collapse if is displaced sideways to higher drift levels than $\Theta_{\text {fail }, 1}=0.16 \%$; this would be expected to occur for the calculated cases of $a_{g}=0.36 \mathrm{~g}, 0.48 \mathrm{~g}, 0.60 \mathrm{~g}$. The peak ground accelerations recorded near the school sites during the Bingöl earthquake was $a_{g}=0.28 \mathrm{~g}$ in the East-West direction and $a_{g}=0.55 \mathrm{~g}$ in the North-South direction. From the eleven school buildings having the typical floor plan of Figure 8, three collapsed, six were severely damaged and two were moderately damaged [14]; (the orientation of the building relative to the earthquake directivity most likely was a decisive factor regarding collapse).

Residential building: The vulnerability curves that relate the composite dimensionless index of area of the vertical floor members for various levels of drift, $\Theta_{l}$, are those shown in

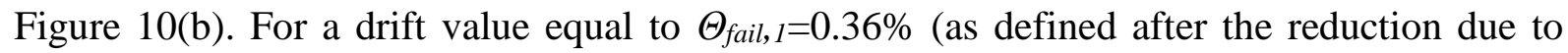
premature failure in shear) demand is defined by the black arrows of Figure 10(b). The percentage of columns, $\rho_{c, i}$, was estimated to be equal to $\rho_{c, i}=0.98 \%$. Since the ground storey had a commercial use, the percentage of the masonry infill walls may be assumed equal to zero, $\rho_{w m, i}=0 \%$, and thus only the percentage of columns of the three storey frame, $\rho_{c, i}=0.98 \%$, was to be considered in the assessment.
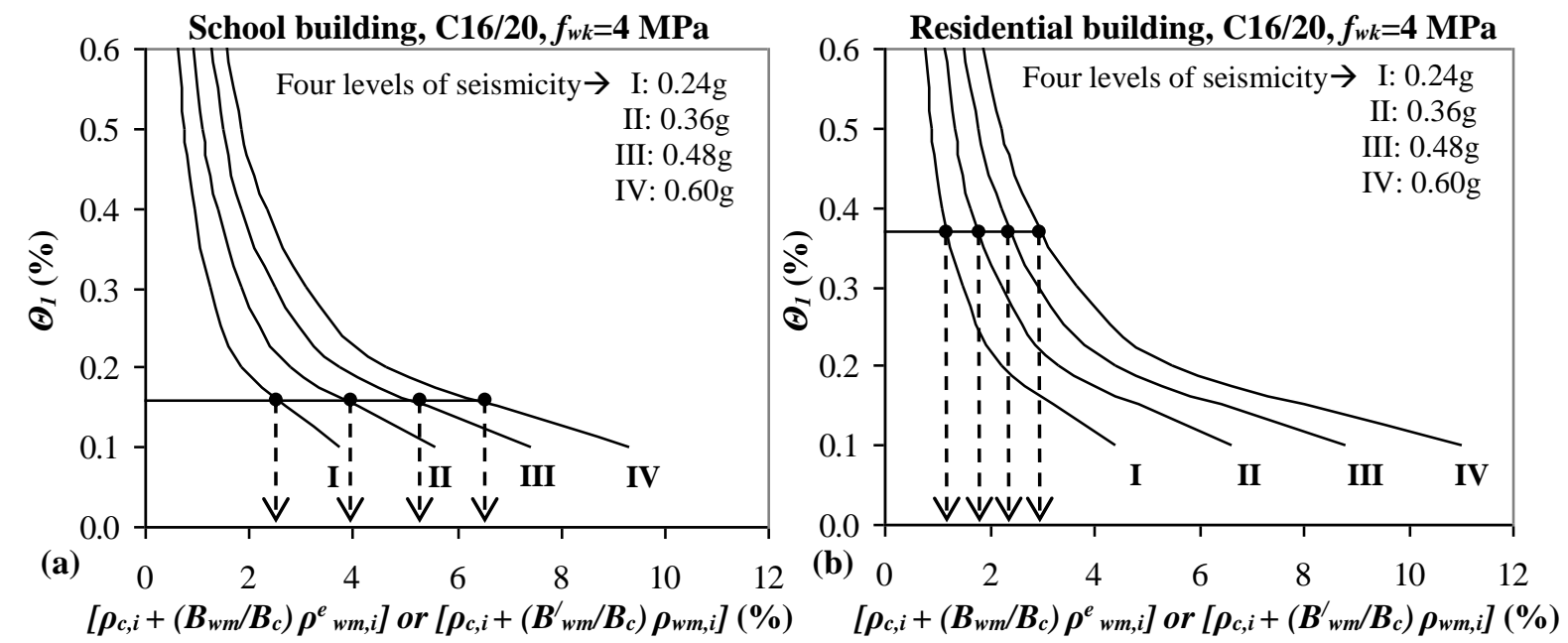

Figure 10. Vulnerability curves that relate the composite dimensionless index of area of the vertical floor members for various levels of drift, $\Theta_{l}$ for the (a) school building; (b) residential building. 
In light of the above, requirements in terms of the area ratio of columns, $\rho_{c, i}$, for $\Theta_{\text {fail }, 1}=0.36 \%$ is equal to $1.2 \%, 1.9 \%, 2.5 \%$ and $3.1 \%$ for $a_{g}=0.24 \mathrm{~g}, 0.36 \mathrm{~g}, 0.48 \mathrm{~g}$ and $0.60 \mathrm{~g}$, respectively (Figure 10(b)). This leads to the conclusion that the percentage of the columns is insufficient for all the seismicity levels considered in this study.

\section{SUMMARY - CONCLUSIONS}

A simple assessment methodology that is intended for rapid identification of seismically deficient structures is developed in this paper. The method is simple to use and requires only rudimentary information and data for the assessed structure; it is not meant to replace detailed assessment, but it is proposed as a simple versatile tool that can be used by structural engineers with basic training, without necessarily requiring access to sophisticated structural analysis software. The proposed methodology is particularly suitable for cases where only estimates of member details are known due to the lack of design drawings. It can be particularly useful in countries with a high seismicity and a large inventory of substandard construction, in order to single out potentially dangerous buildings that need further evaluation.

First the interstorey drift demand posed by the design earthquake is estimated from the structural period. Through its relation to structural stiffness, this is shown to depend on the area ratio of vertical elements in the critical storey of the structure, and on the number of floors. The area ratio of vertical elements comprises properly adjusted contributions of the area of columns, walls and infills in the direction of seismic action. (Good engineering judgment is required in this step, in order to identify all the levels heightwise where the area ratio need be checked, such as, for example, the level of potential short column formations, if such exist). The next step requires evaluation of the potential for premature shear failure (prior to flexural yielding). This requires information about approximate arrangement of stirrups in the columns, which, however, in most cases typifies the construction practices of the era and the region where the building is located.

If premature shear failure is estimated, then the interstorey drift capacity is calculated from the drift at yielding scaled down to the ratio of shear strength divided by the flexural yield strength of the critical floor.

Assessment therefore is based on the comparison between estimated interstorey drift demand and drift capacity, evaluated as listed above. Higher area ratios of vertical elements in the critical floor lead to reduced drift demands, and therefore the design charts presented in the paper can also be used to guide rehabilitation. Alternatively, given the basic data of the structural geometry, the peak ground acceleration that may be sustained without collapse can also be estimated. The method is general enough and can be expressed as a simple criterion regarding the area ratio of vertical members in a floor required in order to limit drift demand below a tolerable level; the same concept is adjusted to be applied to the level where captive columns (if such exist) are located within a floor. The paper includes examples demonstrating application of the proposed methodology in lightly reinforced buildings that collapsed during recent earthquakes, highlighting the simple efficiency of the required calculations.

\section{APPENDIX}

Expressions for estimating the stiffness for R.C. columns, $K_{i}^{c}$, R.C. walls, $K_{i}^{w c}$, and masonry infill walls, $K_{i}^{w m}$ :

R.C. Columns: The total lateral stiffness of the floor columns is (where $I_{\text {gross }, j}=A_{c, j} \cdot b_{j} / 3$ ): 


$$
K_{i}^{c}=\sum_{j=1, n_{c}} K_{i, j}^{c} \approx E_{c} A_{f} /\left(100 \cdot h_{i}\right) \rho_{c, j}
$$

(Assuming cracked sectional stiffness, $I_{c, j}=I_{\text {gross }, j} / 3$, and a members' aspect ratio of about 6.) R.C. walls: The total translational stiffness of $k$-walls of a single storey parallel to the direction of lateral translation, assuming that the cross section area of the wall is given as a fraction of the plan area $\left(A_{w, k}=\rho_{w, k} A_{f}\right)$ and taking for safety coefficient $\alpha=3$ (coefficient $\alpha$ denotes the restraint conditions of the wall, i.e. $\alpha=12$ for a fixed wall in the upper and lower diaphragm, $\alpha=3$ for a cantilever wall), is expressed as [4]:

$$
K_{i}^{w c}=\sum_{k=1, n_{w c}} K_{i, k}^{w c}=\frac{E_{c} A_{f}}{h_{i}} \sum_{k=1, n_{w c}} \frac{\rho_{w c, k}}{\left(4 h_{i}^{2} / l_{w, k}^{2}+2.50\right)} \approx \frac{E_{c} A_{f}}{h_{i}}\left(\frac{1}{\left(4 h_{i}^{2} / l_{w, a v e}^{2}+2.50\right)} \rho_{w c, i}\right.
$$

Masonry infill walls: In case of frame R.C. structures secant stiffness of the masonry infill wall is defined as the ratio of its shear strength $V_{w, k}$ over the horizontal relative displacement of the wall panel as it distorts. This is equal to the product of interstorey drift by storey height. For the displacement magnitudes for which the building is checked (yielding of R.C. frames occurs approximately at an interstorey drift of about $0.5 \%$ ), the translational interstorey drift is considered to have far exceeded the low value of yield distortion of an individual wall panel, which is estimated roughly to be equal to $0.2 \%$ of its height. Using the expression for wall shear strength $V_{w, k}$ of EC8 [11], the secant lateral stiffness of a masonry infill wall is estimated from:

$$
K_{i}^{w m} \approx 0.1 \cdot A_{f} \cdot f_{w k} \sqrt{1+h_{i}^{2} / l_{w, a v e}^{2}} /\left(\Theta_{i} h_{i}\right) \rho_{w m, i}
$$

In dual systems, where the lateral stiffness of the storey comprises the stiffness of columns, walls and infill masonry walls, the total lateral stiffness of the masonry walls of the floor is estimated from a linear elastic definition:

$$
K_{i}^{w m}=\sum_{p=1, n_{w m}} K_{i, p}^{w m}=/ \frac{E_{m} A_{f}}{h_{i}} \sum_{p=1, n_{w n}} \frac{\rho_{w m, p}}{\left(4 h_{i}^{2} / l_{m, k}^{2}+2.50\right)} \approx \frac{E_{w m} A_{f}}{h_{i}}\left(4 h_{i}^{2} / l_{m, a v e}^{2}+2.50\right)^{\rho_{w m, i}}
$$

\section{NOMENCLATURE}

$A_{c, j} ; A_{w, k}$ cross-sectional area of R.C. columns and R.C. walls, respectively

$A_{f} \quad$ floor area

$A_{\text {infl }} \quad$ tributary area of the floor slab associated with a single column

$A_{s 1, j} \quad$ tensile longitudinal reinforcement

$A_{s t, j} \quad$ cross-sectional area of stirrup legs in a single stirrup layer

$B_{c} ; B_{w m} ; B_{w m}{ }^{\prime}$ coefficients related to the elastic modulus for R.C. columns, R.C. walls and masonry infill walls and masonry infill walls, respectively (Equations (11) and (14)).

$b_{j} \quad$ width of the cross section

$D_{b} \quad$ longitudinal bar diameter

$d_{j} ; d_{j, a v e}$ depth of the cross section; average depth of the cross section

$E \quad$ elastic modulus

$E_{c} ; E_{w m}$ elastic modulus of concrete and masonry, respectively

$f_{b d} \quad$ bond stress

$f_{c}^{\prime} \quad$ concrete compressive strength 
$f_{s t} \quad$ stirrup stress

$f_{w k} \quad$ compressive strength of masonry

$f_{y} \quad$ yield stress

$f_{y, s t} \quad$ stirrup yield stress

$\hat{g} \quad$ factored distributed load (in $\mathrm{kN} / \mathrm{m}^{2}$ )

$g_{\text {s.w. }} \quad$ average self weight per unit floor area (in $\mathrm{kN} / \mathrm{m}^{2}$ )

$H$ total height of the structure

$h_{c, i} ; h_{\text {capt }}$ column length and length of the captive column at i-th storey, respectively

$h_{i} \quad$ storey height

$h_{j} \quad$ height of the cross section

$i \quad$ radius of gyration of the uncracked concrete section

$I_{c, j} ; I_{b, j} ; I_{w, k}$ moment of inertia of the j-th column, j-th beam and $\mathrm{k}$-th wall, respectively

$I_{j}$; $I_{\text {gross }, j}$ moment of inertia of the $\mathrm{j}$-th member and of the gross cross section, respectively

$K \quad$ stiffness of the building

$K_{j}^{c} ; K_{k}^{w c} ; K^{w m}{ }_{p}$ stiffness for R.C. columns, R.C. walls and masonry infill-walls, respectively

$K_{i} \quad$ stiffness of i-th storey

$L_{b} \quad$ standard straight anchorage length for the bar diameter of the ties considered

$L_{b, a} \quad$ available anchorage length of the tie measured from the point where it is intercepted by a diagonal crack to the end hook

$L_{b, i} \quad$ beam length at i-th storey

$l_{m, a v e} ; l_{w, \text { ave }}$ average length of masonry and R.C. wall, respectively

$\ell_{o} \quad$ unsupported column length

$L_{s} \quad$ shear span length

$M_{i} \quad$ mass of the i-th storey

$M_{y, j} \quad$ flexural strength at yield of the j-th member

$n \quad$ number of storeys

$n_{b} ; n_{c} ; n_{w c} ; n_{w m} ;$ number of beams, columns, walls and masonry infill walls, respectively

$N_{j}$; $N_{\text {total }}$ axial load of the $\mathrm{j}$-th member and total axial load of the storey, respectively

$q \quad$ behavior factor (Here elastic response is considered, so $q=1$ )

$Q_{i} \quad$ coefficient that expresses the square root of mass over stiffness of the ESDOF system (Equations 18(a) and 18(b))

$s \quad$ distance of stirrups

$S \quad$ soil parameter

$S_{a} ; S_{d}$ spectral acceleration and displacement, respectively

$T$ period

$T_{B ;} T_{C}$ period values that define the limits of the constant acceleration branch

$t_{f} \quad$ equivalent thickness of the horizontal diaphragm

$V_{R d, t o t} ; V_{R d, c a p t}$ nominal shear strength for full height and captive columns, respectively

$V_{\text {shear } ;}$ shear strength of the j-th member

$V_{w, j}{ }^{s t} \quad$ shear strength of the web reinforcement

$V_{y, t o t} ; V_{y, \text { capt }}$ nominal shear strength at flexural yielding of full height and captive columns, respectively

$W_{f} \quad$ factored vertical load of the typical i-th storey

$W_{\text {tot }}$ total weight of the structure

$x_{j} \quad$ compression zone depth

Greek Symbols

$\alpha \quad$ modifying coefficient that denotes the restraint conditions of the wall-ends

$\alpha_{g} \quad$ peak ground acceleration (pga)

$\beta_{o} \quad$ spectral acceleration amplification factor equal to 2.5

$\gamma \quad$ mass per unit area of the floor $\left(\gamma=g / 10 \mathrm{~m} \cdot \sec ^{-2}\right)$ 
$\gamma_{c} \quad$ mass density of reinforced concrete $\left(=25 \mathrm{kN} / \mathrm{m}^{3}: 10 \mathrm{~m} / \mathrm{sec}^{2}\right)$

$\gamma_{e l} \quad$ coefficient equal to 1.15 for primary seismic elements

$\delta_{j} \quad$ coefficient that estimates the local increase/decrease in the tributary plan area of the column

$\Delta \Phi_{i} \quad$ the difference in the shape between successive floors

$\varepsilon_{s y} \quad$ steel strain at yield

$\theta_{i} ; \theta_{j}{ }^{l} ; \theta_{j}{ }^{2}$ chord rotation of the i-th storey and chord rotations at the member ends 1 and 2 , respectively

$\Theta_{f a i l, i}$ drift of i-th storey at failure

$\Theta_{f a i l, i}$ shear drift of i-th storey at failure due to brittle elastic shear failure

$\Theta_{i} ; \Theta_{1}$ drift of i-th storey and drift of the first storey, respectively

$\Theta_{y, j} ; \Theta_{y, \text { ave }}$ drift of j-th member at yield and average drift of i-th storey at yield, respectively

$\lambda_{s} \quad$ slenderness of vertical members

$\lambda \quad$ relative stiffness ration of the $n_{b}$ beams and the $n_{c}$ columns the converge at a typical floor joint

$\mu_{\Delta}{ }^{p l} \quad$ plastic displacement ductility (For the onset of flexural yielding, where the displacement ductility $=1$, it follows that $\mu_{\Delta}^{p l}=0$; for a displ. ductility of $3, \mu_{\Delta}^{p l}=2$ )

$v_{j}$; $v_{\text {ave }}$ dimensionless axial load and average value of the dimensionless axial load, respectively

$\xi_{j} \quad$ normalized depth of compression zone

$\rho_{c, i} \quad$ columns' area ratio in the floor plan

$\rho_{\ell, t o t, j} \quad$ longitudinal reinforcement ratio over the column section of $\mathrm{j}$-th member

$\rho_{\min } \quad$ minimum area ratio of vertical members required in order to avoid damage

$\rho^{e}{ }_{w m, i}$ equivalent dimensionless area for masonry walls and R.C. walls expressed in terms of masonry walls

$\rho_{w c, i} ; \rho_{w m, i}$ dimensionless area of R.C. walls and masonry infill walls at i-th storey

$\Sigma A_{c} \quad$ total cross sectional area of the columns in a typical floor

$\varphi_{y, j} \quad$ curvature at yield of the j-th member

$\Phi ; \Phi_{1}$ lateral deflection shape and lateral deflection shape of the first storey, respectively

$\omega \quad$ cyclic frequency

$\omega_{\ell} \quad$ mechanical ratio of longitudinal reinforcement over the column section

\section{REFERENCES}

1. EAK. Greek earthquake resistant design. Ministry of Environment, Planning and Public Works 2000, Athens, Greece (in Greek).

2. RD. Earthquake design regulation of building works. Royal Decree (19/26.02.1959) 1959, Ministry of Public Works, Greece (in Greek).

3. Shiga T, Shibata A, Takahashi T. Earthquake damage and wall index of reinforced concrete buildings.). Proceedings of the Tohuku District Symposium 1968, Architectural Institute of Japan, 12: 29-32 (in Japanese).

4. Gülkan P, Sozen MA. Procedure for determining seismic vulnerability of building structures. ACI Structural Journal 1996; 96(3): 336-342.

5. Yakut A. Preliminary seismic performance assessment procedure for existing R.C. buildings. Engineering Structures 2004; 26(10): 1447-1462.

6. Yakut A, Gulkan P, Sadik Bakir B, Tolga Yilmaz M. Re-examination of damage distribution in Adapazari: Structural considerations. Engineering Structures 2005; 27(7): 990-1001.

7. Eurocode 2. Design of concrete structures - Part 1-1: General rules and rules for buildings. prEN 1992-1-1:2003E 2003, European Committee for Standardization (CEN), Brussels.

8. Thermou GE, Pantazopoulou SJ, Elnashai AS. Design and assessment models and spectra for repaired reinforced concrete structures. MAE Center report 2009; CD release 09-01. 
9. Eurocode 8. Design of structures for earthquake resistance - Part 1: General rules, seismic actions and rules for buildings. EN1998-1-2004:E 2004, European Committee for Standardization (CEN), Brussels.

10. Tastani SP, Pantazopoulou SJ. Recovery of seismic resistance in corrosion-damaged reinforced concrete through FRP jacketing. International Journal of Materials and Product Technology 2005; 23(3/4): 389-415.

11. ACI 318-08. Building code requirements for reinforced concrete and commentary. American Concrete Institute, Farmington Hills Michigan, 467.

12. Eurocode 8. Design of structures for earthquake resistance - Part 3: Assessment and retrofitting of buildings. EN1998-3-2005:E 2005, European Committee for Standardization (CEN), Brussels.

13. fib Bulletin 24. Seismic assessment and retrofit of reinforced concrete buildings. State of the art report 2003, federation international du béton (fib), Lausanne Switzerland, 312.

14. Pantazopoulou V, Syntzirma D. Code expressions for deformation capacity of lightly reinforced concrete members - a comparative study. ACES Workshop: Advances in Performance-Based Earthquake Engineering 2009, Corfu, Greece.

15. Gür T, Pay AC, Ramirez JA, Sozen MA, Johnson AM, Irfanoglu A, Bobet A. Performance of school buildings in Turkey during the 1999 Düzce and the 2003 Bingöl earthquakes. Earthquake Spectra 2009; 25(2): 239-256

16. Ramirez JA, Yakut A, Akyuz U, Gür T, Irfanoglu A, Matamoros A, Ozcebe G, Sozen MA, Turer A, Wasti ST. Types of structures and observed damage (Chapter 5). 1 May 2003 Bingöl Earthquake Engineering Report 2003, Technical Editors: Ozcebe G, Ramirez J, TanvirWasti S, Yakut A, TUBITAK, NSF (http://www.anatolianquake.org).

17. Priestley MJN. Brief comments on elastic flexibility of reinforced concrete frames and significance to seismic design. Bulletin, New Zealand National Society for Earthquake Engineering 1998; 31(4): 246-259.

18. Priestley MJN, Kowalsky MJ. Aspects of drift and ductility capacity of cantilever structural walls. Bulletin, New Zealand National Society for Earthquake Engineering 1998; 31(2): 73-85.

19. Deutsches Institut für Normung (DIN). Beton un Stahlbetonbau: Bemessung und Ausführung. DIN 1045 1972, Berlin.

20. Deutsches Institut für Normung (DIN). Betonstahl. DIN 488 (1975), Berlin. 